\title{
PARTICIPATION IN FRAUDULENT ELECTIONS
}

\author{
Dmitriy Vorobyev
}

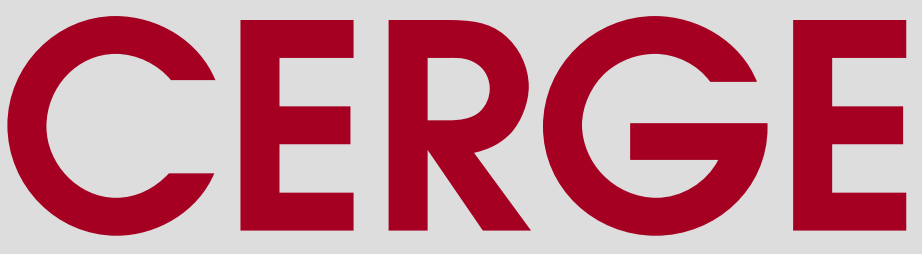

Cha rles University

Centerfor Economic Research and Graduate Education

Academy of Sciences of the Czech Republic

Ec onomic Institute 


\title{
Working Paper Series 510 (ISSN 1211-3298)
}

\section{Participation in Fraudulent Elections}

\author{
Dmitriy Vorobyev
}

CERGE-EI

Prague, February 2014 
ISBN 978-80-7343-314-7 (Univerzita Karlova. Centrum pro ekonomický výzkum a doktorské studium)

ISBN 978-80-7344-307-8 (Akademie věd České republiky. Národohospodářský ústav) 


\title{
Participation in Fraudulent Elections
}

\author{
Dmitriy Vorobyev*广
}

February 2014

\begin{abstract}
I analyze a costly voting model of elections, in which the incumbent can stuff the ballot box, to investigate how electoral fraud affects the participation decisions of voters. I find that two stable equilibria may exist: first, a full abstention equilibrium, where the incumbent wins with certainty, which exists only if the incumbent's capability to stuff a ballot box is sufficiently strong. Second, a more efficient coordination equilibrium, where a substantial share of a challenger's supporters vote and the probability of the incumbent being defeated is large. Since voters do not take into account positive externality they produce on other voters when deciding to cast their votes, participation in coordination equilibrium is still inefficiently low. Thus, subsidization as well as introducing compulsory voting may improve efficiency. Because the higher capability of the incumbent to stuff a ballot box discourages the participation of his own supporters and creates coordination incentives for the challenger's supporters, higher fraud does not always benefit the incumbent, even when costless. Additionally, the model simultaneously explains two empirical observations about fraudulent elections: a positive relationship between fraud and victory margin and a negative effect of fraud on turnout.
\end{abstract}

JEL Classification: D72, D73

Keywords: Voting, Fraud, Participation

*Graduate School of Economics and Management, Ural Federal University, Ekaterinburg, Russia.

${ }^{\dagger}$ CERGE-EI, a joint workplace of the Center for Economic Research and Graduate Education, Charles University, and the Economics Institute of Academy of Sciences of the Czech Republic. Address: CERGE-EI, P.O. Box 882, Politických vézñu 7, Prague 1, 111 21, Czech Republic. 


\begin{abstract}
V článku zkoumáme, jaký vliv má podvod ve volbách na rozhodnutí voličů o účasti. Analyzujeme nákladný hlasovací model voleb, kde stávající držitel hlasu může do volební urny přidávat hlasy. Zjištujeme, že na rozdíl od nezmanipulovaných voleb, kde obvykle existuje jediná rovnováha, mohou existovat dvě stabilní rovnovážné situace: rovnováha dosažená plnou neúčastí, kdy stávající držitel hlasu vyhrává s jistotou, a která existuje pouze v případě, že schopnost stávajícího držitele hlasu naplnit volební urnu je dostatečně silná; a účinnější koordinační rovnováha, kdy hlasuje podstatná část podporovatelů vyzyvatele a pravděpodobnost porážky stávajícího držitele hlasu je vysoká. Vzhledem k tomu, že voliči neberou v úvahu pozitivní externality, násobí svůj vliv na ostatní voliče, aby odevzdali své hlasy; účast na koordinační rovnováze je přesto neefektivně nízká, a proto její produktivitu může zlepšit dotace (sponzorování) nebo zavedení povinné účasti ve volbách. Vzhledem k tomu, že skutečnost, že stávající držitel hlasu má lepší možnost doplnit ve volbách hlasy neexistujících voličů, odrazuje od účasti jeho vlastní podporovatele, a vede k vytváření koordinovaných pobídek na straně podporovatelů jeho vyzyvatele, vyšší míra podvodu není stávajícímu držiteli hlasů vždy ku prospěchu, i s ním nejsou spojeny žádné náklady. Model zároveň vysvětluje dvě empirická pozorování týkající se voleb, jejichž součástí byl podvod: pozi-tivní vztah mezi podvodem a převahou hlasů potřebnou k vítězství (tzv. victory margin) a negativní dopad podvodu na účast ve volbách.
\end{abstract}




\section{Introduction}

Participation in elections has been widely studied by economists. Why do voters vote? How do they make their decisions to participate or abstain? Is the participation level in voluntary elections efficient or are there too many or too few voting? What electoral policies may improve efficiency? Researchers have been addressing these questions for decades.

Though approaches to modeling and analyzing the behavior of voters differ, they all share one common feature: it is assumed that elections are well-functioning mechanisms for converting public preferences into social choice, and that the outcomes of elections are fully determined by votes casted for the candidates. However, in reality fraud has become an integral part of electoral competition in both established democracies and less-than-democratic regimes. In recent years both economists and political scientists have started paying closer attention to elections that lack integrity, but there are still plenty of open questions on all sides of the electoral game in a fraudulent context, including the impact of fraud on the participation incentives of voters. In this paper I theoretically analyze how the presence of fraud affects voters' participation decisions and thus social welfare, and explain several puzzling empirical observations about fraudulent elections.

Indeed, if voters anticipate that elections will be tainted by fraud, their decisions must be different. In fact, there is a substantial body of empirical evidence suggesting that voters behave differently in fraudulent elections than they do in 'clean' elections. They are less likely to participate in fraudulent elections, for example. This observation has been verified by McCann and Dominguez (1998), Hiskey and Bowler (2005), and more recently by Simpser (2012) on the example of Mexico, by Birsch (2010), in a study of cross-country electoral survey data from both new and established democracies, and by Landry, Davis and Wang (2010) on the example of elections in China. Though it is well-established that voters reach different decisions in fraudulent elections, the mechanism which leads to these differences has not been investigated in any depth, and the literature on fraudulent elections at best simply assumes that voters have stronger incentives to abstain if they expect fraud.

While the behavior of voters in a fraudulent context has not garnered much attention in the academic literature, the behavior of candidates has been studied fairly well. The literature generally considers fraud to be more than just a means of getting extra votes, and often models it as political pressure or violence. The main question raised by scholars is why and when corrupt incumbents choose to use political pressure in electoral competition. Chatuverdi (2005), for example, studies a competition between parties which can allocate resources between ideological campaigning and political violence. He shows that competing parties use more political pressure if the outcome of elections is more uncertain ex-ante. Once there is a bias towards one candidate 
in terms of support, competing parties prefer to gain votes through ideological campaigning. Magaloni (2010) focuses on the incentives of a corrupt incumbent to hold clean elections, and shows that under substantial threat of revolt, incumbents prefer to avoid fraud. Recently, Collier and Vicente (2012) have distinguished several illegal strategies used by candidates to affect the outcome of elections, including violence, repression, and electoral manipulations, and show that the choice of strategy adopted depends on the strength of the candidates' support: a weak challenger would prefer to use violence and a weak incumbent would use repression, while an incumbent with strong support would prefer to bribe electoral officials and stuff the ballot box.

Instead of considering fraud as political pressure or violence which affects voters' or candidates' utility, I suggest thinking about it as ballot stuffing. In such a setup voters do not directly suffer from an incumbent's actions but instead anticipate that if they abstain, their votes are likely to be counted in favor of the corrupt incumbent. Such an approach allows me to focus on the effect of fraud on voters' behavior from a purely pivotal perspective.

I therefore model electoral fraud as ballot stuffing, assuming that if a voter does not participate in elections, his unused ballot may be transformed into a vote for the incumbent. Indeed there is a wide range of technologies for rigging elections, and ballot stuffing is just one of them ${ }^{1}$. From the modeling perspective, the variety of fraud technologies which directly influence the reported vote shares of the candidates may be divided into three groups according to the underlying mechanism of lending an advantage to the incumbent. Techniques from the first group transform votes cast for the challenger into votes for the incumbent. This category includes rigging the software for electronic voting machines or designing the ballot so that it consistently leads voters to vote for another candidate than they prefer $^{2}$. The second group utilizes technologies that reduce the number of votes cast for the challenger, such as invalidation and destruction of ballots for wrong candidates. The third group of technologies consists of techniques that directly or indirectly ${ }^{3}$ transform unused ballots into additional votes for the incumbent: ballot stuffing, multiple voting, and vote buying, for example.

Though direct evidence is hard to find, the methods of the last group of techniques are likely to be more widespread and account for a larger share of fraudulent activities than the methods from the other two groups, which are much less cost effective and far more limited in adding to the incumbent's advantage. Modeling fraud technology as adding extra votes for the incumbent at the expense of voters who do not participate is, therefore, the most natural way to proceed. In the rest of the paper I thus refer to the fraud technology used in my model

\footnotetext{
${ }^{1}$ See, for example, Lehoucq (2003) for the description of electoral irregularities observed in various elections.

${ }^{2}$ The infamous Florida butterfly ballot in the US 2000 Presidential elections is an example.

${ }^{3}$ I label a technology indirect if it does not literally convert unused ballot papers into votes, but the number of extra votes that the incumbent may get through it is limited by the number of unused ballots, since reported turnout cannot exceed $100 \%$.
} 
as ballot stuffing, though it also accounts for multiple voting, vote buying, and all other fraud techniques that increase the number of votes for the incumbent using, directly or indirectly, the actual ballots of voters who abstained from voting.

I analyze a pivotal costly voting model of elections, in which the incumbent can stuff a ballot box, to investigate how the behavior of voters would change if they know that, were they to abstain, their votes may be counted in favor of the incumbent. I further investigate what the welfare consequences of this change are, what may be done in order to increase welfare, and how the incumbent would behave if he anticipates voters' response to fraud.

The main findings are the following:

1) Two stable equilbria may exist: an equilibrium with full abstention, where none of the voters vote and the incumbent wins with probability 1 , and a coordination equilibrium where a positive share of the challenger's supporters votes, and the probability that the incumbent will lose is high. Full abstention equilibrium exists only when the incumbent's capability to stuff a ballot box is sufficiently large.

2) Coordination equilibrium is likely to deliver higher welfare than full abstention equilibrium. Participation in coordination equilibrium is below an efficient level, since voters do not take into account the positive externality they produce on other voters when making participation decisions. Subsidy and, in some cases, introducing compulsory voting may improve efficiency.

3) Higher capability of the incumbent to stuff the ballot box discourages the participation of the incumbent's supporters, requires stronger coordination among the challenger's supporters, and leads to higher participation of the supporters of the challenger, conditional on coordination being achieved.

4) Higher fraud capability does not always benefit the incumbent, even when costless.

The rest of the paper is organized as follows. In the next section I describe a pivotal private value model of costly voting, where voters decide whether to participate in elections or abstain by comparing their individual specific voting costs with the expected benefit, which involves a probability to cast a decisive vote, i.e. to be pivotal. I then analyze the case where the incumbent can stuff a ballot box perfectly. I show that in addition to the full abstention equilibrium, where none of the voters vote, the incumbent stuffs $100 \%$ of votes, and wins with probability one, a relatively more efficient stable coordination equilibrium exists, where a substantial share of the challenger's supporters vote, the number of stuffed ballots is relatively low, and the challenger is likely to win. After characterizing properties of the equilibria, I focus on welfare and show that in a coordination equilibrium voters' participation is inefficiently low, since the voters ignore the externality they produce on other voters when making voting decisions, and thus, subsidizing participation or even introducing compulsory voting may improve welfare. I then generalize the 
model by allowing fraud to be imperfect. Instead of assuming that the vote of a non-participant is stuffed in favor of the incumbent with certainty, I assume that the incumbent can steal a non-participant's vote with some probability, which can be thought of as the incumbent's fraud capability. This generalization allows me to analyze the whole range of elections, from clean to totally fraudulent, though it makes the analytical solution extremely challenging to obtain. I explore how changes in this probability affect properties of the equilibria, and then study the choice of the incumbent if he is free to choose his fraud capability. In the final section, I discuss how the model fits the empirical evidence regarding fraudulent elections and argue that it can explain several puzzling observations such as a positive relationship between fraud and victory margins and a negative effect of fraud on turnout.

\section{The Model}

Participation in fraudulent elections is analyzed within a pivotal voting framework. Elections are modeled in a way similar to a large body of pivotal costly voting literature, where voters are assumed to make participation decisions based on the probability that their votes can alter the outcome of elections. Costly private value voting models of a similar type have been widely studied by, for example, Palfrey and Rosenthal (1983, 1985), Ledyard (1984), Borgers (2004), and more recently by Krasa and Polborn (2009) as well as Taylor and Yildirim (2010).

\subsection{Setup}

There are $N$ voters $(N \geq 2)$ and two candidates to vote for, the incumbent $(\mathrm{A})$ and the challenger (B). Voters have preferences for candidates: $B$ voters support the challenger (B-type) and $N-B$ voters favor the incumbent (A-type). Each voter has an individual specific voting cost $c_{i}$ drawn from a commonly known distribution $F$ over interval $\left(0, c_{\max }\right]$ where $c_{\max } \leq 1$, independently of his type and other voters. Distribution $F$ is assumed to be continuous with positive density over $\left(0, c_{\max }\right)$ and differentiable cdf. $F$ admits probability density function $f$ which must have no more than one local maximum. If a voter's preferred candidate wins, the voter gains utility 1 if he did not vote, and $1-c_{i}$ otherwise. If his favored candidate loses, the voter gains utility 0 if he abstained, and $-c_{i}$ if he voted. Every individual observes his own cost only. In this model, the supporters of the incumbent and those of the challenger differ ex-ante only in their preferences regarding candidates, while all their other characteristics such as benefits from electing a favored candidate and expected voting costs are the same.

Elections are run under majority rule and, without loss of generality, a tie is resolved in favor of the incumbent. Elections are fraudulent: the incumbent is able to commit fraud through 
ballot stuffing, meaning that if a voter abstains, his unused ballot may be counted in favor of the incumbent with certain exogenously given probability $\alpha \in[0,1]$.

Note that if $\alpha=0$, my model becomes almost identical to the models by Krasa and Polborn (2009) and by Borgers (2004), differing from them only in the assumption on known numbers of supporters for each candidate ${ }^{4}$ Krasa and Polborn (2009) as well as Borgers (2004), in contrast, assume that the levels of supports of the candidates are ex-ante unknown, and every voter may be of either A-type or B-type with certain commonly known probability ${ }^{5}$. To be fully consistent with both models, I allow for ex-ante unknown levels of support in the generalized version of my model analyzed in Section 3, though it does not have any substantial effect either on the logic of the model or on the results. Thus, my model can be thought of as a generalization of the costly voting models by Krasa and Polborn (2009) as well as by Borgers (2004).

\subsection{Analysis}

I first analyze a simplified model, assuming $\alpha=1$, wherein the incumbent stuffs the ballot box perfectly: if a voter abstains, his vote is counted in favor of the incumbent with certainty. Though this assumption might seem too strict, it allows for analytical characterization of the properties of equilibria, and understanding of the intuition behind the electoral game. In Section 3 I relax the assumption on perfect fraud and analyze the general model with arbitrary $\alpha$.

The analysis of voters' behavior in elections with perfect fraud begins from the observation that, conditional on voting, a voter's weakly dominant strategy is to vote for his preferred candidate; thus the analysis focuses on participation decisions only.

Further note that none of the incumbent's supporters have incentives to vote as long as the costs of voting are non-negative. This is because an A-type voter's vote will be counted in favor of the incumbent regardless of whether the voter participates or abstains. Relaxing the assumption on non-negative costs will be discussed further.

Thus, I restrict my attention to the voting behavior of the challenger's supporters. First, note that a B-type voter $i$ decides to vote if and only if his expected benefit exceeds his participation cost:

$$
\Pi(p)>c_{i}
$$

$\Pi(p)$ is the voter's probability of being pivotal given that a randomly chosen B-type voter votes with probability $p$, and, at the same time, expected benefit because the voter's benefit from

\footnotetext{
${ }^{4}$ Both Borgers (2004) and Krasa and Polborn (2009) assume that a tie is resolved with a toss of a coin, while I assume that a tie is resolved in favor of the incumbent, but this difference is purely technical and does not crucially affect any result.

${ }^{5}$ In Borgers (2004) the probability that a voter is of a certain type is 0.5, while in Krasa and Polborn (2009) this probability is arbitrary. Thus, Borgers' model is a special case of the model by Krasa and Polborn.
} 
electing the challenger is 1 . In this paper I focus on within-group symmetric equilibria where all the voters of the same type adopt the same voting strategy.

Because the number of votes for the incumbent is at least as large as $N-B$ (number of A-type voters), there is no way the challenger can win elections if the number of his supporters is less than $N-B+1$. Thus, if $B<N-B+1$, B-type voters do not have incentives to vote either, and the unique equilibrium is full abstention. The interesting case to analyze is the situation when $B \geq(N+1) / 2$.

To build the pivotal probability $\Pi(p)$ function, let $V$ be a number of individuals other than $i$ who choose to vote. Thus, $V$ is a random variable that follows a binomial distribution with parameters $B-1$ and $p$. The probability that $V$ takes a particular value $v$ is then:

$$
\operatorname{Prob}(V=v)=\left(\begin{array}{c}
B-1 \\
v
\end{array}\right) p^{v}(1-p)^{B-v-1}
$$

A B-type voter is pivotal when, in case of his abstention, the numbers of votes for the incumbent and challenger are equal, or when the challenger lacks one vote, which implies that the number of B-type participants must be $N / 2$ if $N$ is even, or $(N-1) / 2$ if $\mathrm{N}$ is odd.

Without loss of generality, assume $N$ is even, since all further calculations can be straightforwardly adjusted for the case when $N$ is odd. Then, the voter is pivotal if and only if $V=N / 2$. Note that $N / 2+1 \leq B \leq N$ as the number of B-type voters should be larger than the number of A-types and smaller than the total number of voters $N$. From (2) we obtain a probability of being pivotal:

$$
\Pi(p)=\operatorname{Prob}(V=N / 2)=\left(\begin{array}{c}
B-1 \\
N / 2
\end{array}\right) p^{N / 2}(1-p)^{B-N / 2-1} .
$$

It can be seen that this function is non-negative, achieves maximum at $p=\frac{N / 2}{B-1}$, equals zero when $p=0$ or $p=1$ whenever $B>N / 2+1$. If $B=N / 2+1$, then $\Pi(p)$ is strictly increasing in $p$.

Given pivotal probability function $\Pi(p)$, it is now possible to characterize equilibrium. I search for a symmetric equilibrium where all B-type voters adopt the same voting strategy. Specifically, there must be a common threshold value $c^{*}$ such that a B-type voter $i$ votes if $c_{i} \leq c^{*}$ and abstains otherwise. Thus, $c^{*}$ should satisfy:

$$
\Pi\left(F\left(c^{*}\right)\right) \geq c^{*}
$$

with equality when $c^{*}<c_{\max }$.

For further analysis the condition can be rewritten as:

$$
\Pi\left(F\left(c^{*}\right)\right) \geq F^{-1}\left(F\left(c^{*}\right)\right)
$$


with equality when $c^{*}<c_{\max }$.

Note that $F\left(c^{*}\right)$ is the expected share of voters with voting costs below $c^{*}$, i.e. those who participate in elections. Thus, $F\left(c^{*}\right)$ is the expected turnout of B-type voters. For further analysis I will use short notation $F\left(c^{*}\right)=p^{*}$. Denoting $F(c)=p$, one can construct a graph in $(p, \Pi(p))$ space.

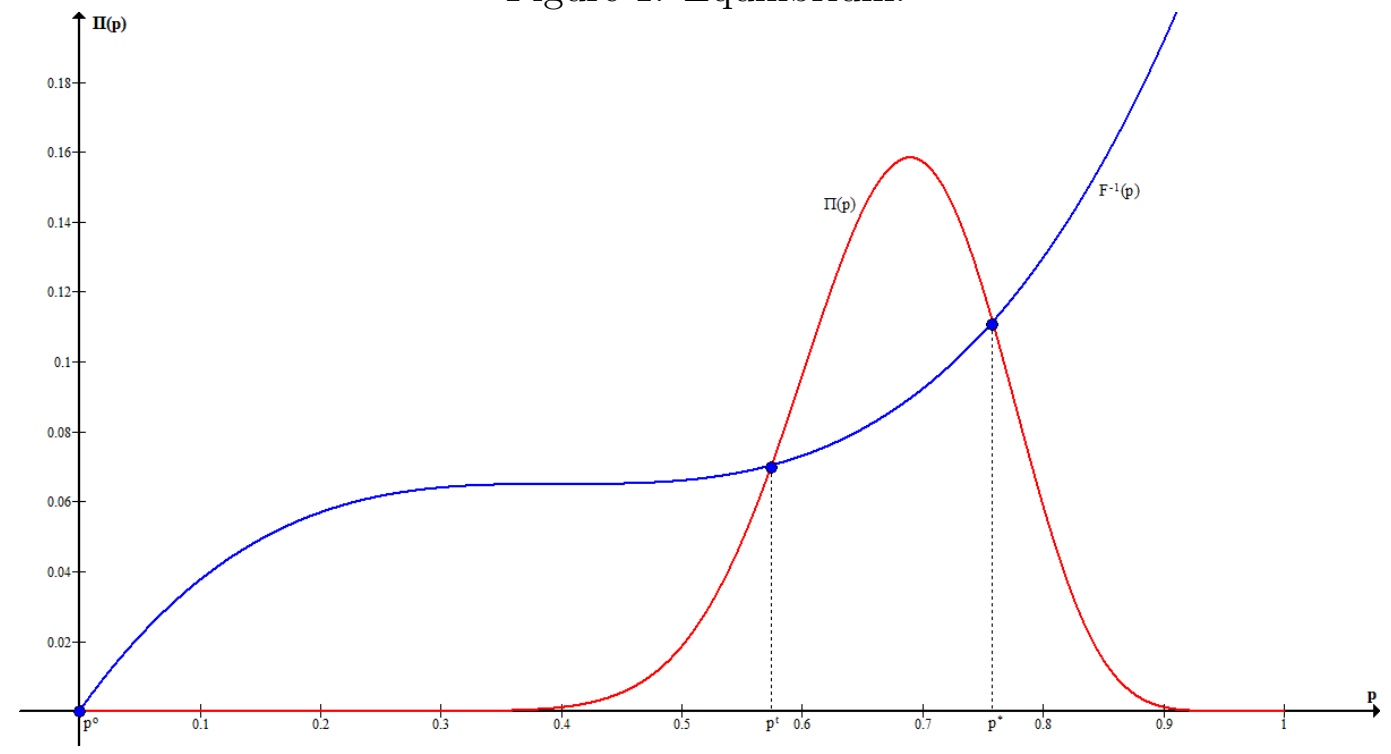

The unimodality of the cost distribution and the assumption on at most one inflection point in this cdf of the distribution together guarantee that there could be up to three points that satisfy equation (5). I denote the arguments of these intersections as $p^{0}, p^{t}$ and $p^{*}$. Note that solution $p^{0}=0$ always exists, while existence of $p^{t}$ and $p^{*}$ (which may coincide under certain conditions) depends on the model's parameters. Equilibrium $p^{0}$ is an equilibrium with full abstention, while in equilibrium $p^{*}$ a strictly positive share of B-type voters participates. Note that $p^{0}$ and $p^{*}$ are stable equilibria, while $p^{t}$ is not: once participation is lower than $p^{t}$ the model will converge to equilibrium $p^{0}$, otherwise - to $p^{*}$. Thus, $p^{t}$ constitutes a participation threshold value, which needs to be enforced in order to achieve stable coordination equilibrium $p^{*}$. From now on I focus on stable equilibria only, and show below that coordination equilibrium $p^{*}$ is likely to be ex-ante more efficient than full abstention equilibrium $p^{0}$, and thus solving the collective action problem of achieving $p^{t}$ turnout level is welfare improving. Finally, note that if $B=N / 2+1, \Pi(p)$ is strictly increasing in $p$, and if further $\Pi(1)>c_{\max }$ all the B-type voters have incentive to vote which corresponds to $p^{*}=1$.

As noted above, while equilibrium $p^{0}$ always exists, the existence of coordination equilibrium $p^{*}$ depends on the model's parameters. Necessary and sufficient conditions for the existence 
of coordination equilibrium $p^{*}$ can be formulated as follows:

$$
\exists p \in(0,1]: \Pi(p)-F^{-1}(p) \geq 0
$$

In terms of exogenous parameters, the following condition is sufficient for the existence of coordination equilibrium:

$$
\Pi\left(\frac{N / 2}{B-1}\right) \geq F^{-1}\left(\frac{N / 2}{B-1}\right) .
$$

Also note that condition (7) implies $p^{t} \leq \frac{N / 2}{B-1} \leq p^{*}$. Conditions under which coordination equilibrium is more likely to exist are summarized in the following proposition.

Proposition 1. Existence.

1. If coordination equilibrium exists for some $N_{0}, B_{0}$ and cost distribution $F_{0}$, then it exists for any $N<N_{0}$ keeping the ratio of the candidates' support levels fixed;

2. If coordination equilibrium exists for some $N_{0}, B_{0}$ and cost distribution $F_{0}$, then it exists for any $F$ which is first-order stochastically dominated by $F_{0}$;

3. For any $N$ and $B$ such that $N / 2<B \leq N$ there exists an infinite number of cost distributions $F$ such that coordination equilibrium exists;

Proof: See the Appendix.

It is easy to understand the proposition using the graph in Figure 1. There are three exogenous components in the model: total number of voters $N$, distribution of preferences for candidates across voters $N-B$ and $B$, and cost distribution $F$. Keeping the ratio of the candidates' support levels fixed, lower $N$ increases function $\Pi(p)$ for all $p$, since with a lower number of voters every individual is more likely to be pivotal. Thus, with a lower number of voters there is greater likelihood to have coordination equilibrium. The effect of a change in support, holding the population fixed, is unclear. An increase in $B$ would imply that the pivotal probability function achieves its maximum at a lower participation level and that the maximum probability itself is lower. This is not sufficient to make any statement about the likelihood of coordination equilibrium existence without imposing further assumptions on cost distribution. Changes in cost distribution affect the $F^{-1}$ graph only. Whenever the right part (for $p \geq 1 / 2$ ) of the inverse cost distribution function shifts down, coordination equilibrium is more likely to exist. From this logic and condition (7) it follows that keeping costs sufficiently low is enough to guarantee the existence of coordination equilibrium.

Given that coordination equilibrium exists, the important question is how its properties depend on population size, candidates' support, and voting costs. Coordination equilibrium is characterized by two values: voting rule $c^{*}$ (which is matched one-to-one to participation level 
$p^{*}$ ) and participation threshold $p^{t}$, which must be enforced in order to guarantee convergence to coordination equilibrium.

Proposition 2. Comparative Statics. If coordination equilibrium exists and sufficient condition (7) holds with inequality, then:

1. Equilibrium participation $p^{*}$ and threshold value $p^{t}$ are decreasing in $B$;

2. $p^{*}$ is decreasing and $p^{t}$ is increasing in $N$, if the support ratio is fixed;

3. If some cost distributions $G$ and $F$ are such that $G$ is first-order stochastically dominated by $F$, then $p^{*}$ is higher and $p^{t}$ is lower for $G$.

Proof: See the Appendix.

Again, Proposition 2 is easy to understand with Figure 1. An increase in $B$ implies a shift of function $\Pi$ to the left and down, moving both intersection points between $\Pi$ and $F^{-1}$ lower. An increase in $N$ results in a shift of $\Pi$ down, which implies higher $p^{t}$ and lower $p^{*}$. If one cost distribution is first-order stochastically dominated by another, then the graph of the first inverse distribution is lower. Intuitively, a higher share of B-types implies that fewer participants are needed to defeat the incumbent. As a result, fewer individuals will participate and a lower number of participants is sufficient to induce coordination. With a higher number of voters, keeping the support ratio fixed, every voter is less likely to be pivotal, and thus fewer voters will participate in equilibrium. Finally, lower costs straightforwardly result in stronger participation incentives.

The model predicts the existence of two stable equilibria: full abstention equilibrium and coordination equilibrium. In full abstention equilibrium, nobody votes and the incumbent steals all the votes through ballot stuffing, winning with a $100 \%$ victory margin. Coordination equilibrium is characterized by a strictly positive participation rate $^{6}$ among the B-type voters. Moreover, the turnout is always expected to be higher than 50\%. Technically, this result follows from condition (7). If the condition is satisfied, then the participation level of B-types must be higher than $\frac{N / 2}{B-1}$, which, given that $N / 2+1 \leq B \leq N$, implies that the expected turnout among the challenger's supporters is more than $50 \%$. Intuitively, the case when fewer than half of B-type voters are supposed to participate cannot be an equilibrium, since this would mean a defeat of the challenger in expectation regardless of the number of A-type voters. Since participation in coordination equilibrium is positive, the number of stuffed ballots is at most $N-\frac{N}{2(B-1)}$, so coordination equilibrium results in ex-ante lower fraud than full abstention equilibrium. Finally, note that in both equilibria, the official reported turnout is always $100 \%$ since all the ballots of

\footnotetext{
${ }^{6}$ Throughout the paper measures of participation and fraud are in ex-ante terms, since the actual number of participants and thus the actual number of stuffed ballots are random variables, whose exact realizations depend on the realization of voting costs.
} 
absentees are converted in favor of the incumbent.

Properties of the full abstention equilibrium, including zero turnout and 100\% victory margin, may seem too extreme. A slight modification of the model would generate a less extreme result but keep the logic and all the established properties unchanged. Starting from Riker and Ordeshook (1968), the voting literature often argues that voters' participation in elections is driven not solely by their likelihood to be pivotal, but also by the utility they derive from voting, which can be thought of as a utility from fulfilling a civic duty. Once such a utility is introduced into my model, the results become less extreme. Technically, such a modification means that a voter now compares his voting costs with the expected benefit plus some utility from voting $d$ :

$$
\Pi(p)+d>c_{i}
$$

Re-arranging the terms, the last expression can be rewritten as $\Pi(p)>\bar{c}_{i}$, where $\bar{c}_{i}=c_{i}-d$ is a net voting cost. In terms of my model this change means that individual voting costs are now distributed over interval $\left[c_{\text {min }}, c_{\max }\right]$, where $c_{\text {min }}<0$. This change implies that all voters with $\bar{c}_{i}<0$, both A-type and B-type, always vote.

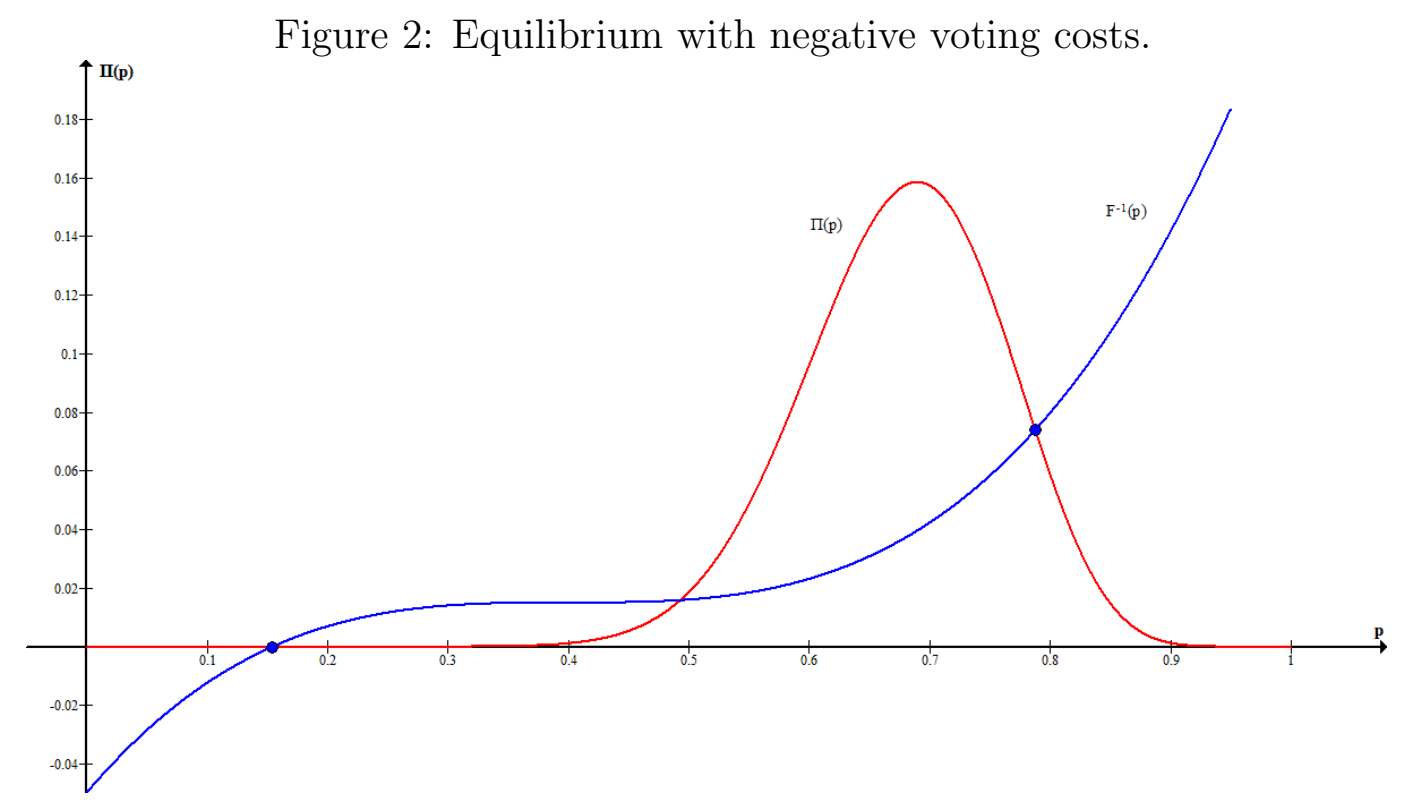

Now, instead of zero participation, the abstention equilibrium is characterized by a strictly positive share of B-type and A-type voters who participate (in expectation) (Figure 2). Note that if there is a sufficient number of vote lovers (those who have negative net voting costs) the first equilibrium may disappear: there are enough B-type voters with negative costs to create participation incentives for voters with positive costs and, thus, to induce coordination equilibrium. Since this is the only property of the model which is substantially affected by 
allowing voting costs to be negative, and all the propositions stated above and below generally stay valid, hereafter I analyze the benchmark model with non-negative costs to avoid unnecessary complications.

Another important characteristic of the equilibria is the probability of the incumbent's victory. Since in full abstention equilibrium, the incumbent stuffs $100 \%$ of ballots, he wins with certainty. His winning in coordination equilibrium depends on the actual turnout of B-type voters. Note that the turnout of B-type voters is a random variable. This is because individual voting costs are independent random draws, with unknown exact realization, and thus the exact number of individuals with costs below some particular threshold is also unknown ex-ante. Given some voting coordination equilibrium rule $c^{*}$, turnout would follow a binomial distribution with parameters $B$ and $F\left(c^{*}\right)$. Thus, the probability that the incumbent defeats the challenger is the probability that no more than $N / 2$ B-type voters cast their votes:

$$
w=\sum_{i=0}^{N / 2}\left(\begin{array}{c}
B \\
i
\end{array}\right) F\left(c^{*}\right)^{i}\left(1-F\left(c^{*}\right)\right)^{B-i} .
$$

Since $B>N / 2$ the winning probability is less than 1 , and it is decreasing in participation of challenger's supporters ${ }^{7}$. Moreover, since in expectation more than $N / 2$ B-type voters participate, the probability that the incumbent will win cannot exceed 0.5. Finally, note that the equilibrium participation of the B-type voters is higher than $\frac{N / 2}{B-1}$, and thus an upper bound for $w$ can be obtained, which is obviously decreasing in the number of the challenger's supporters and increasing in the number of the incumbent's supporters:

$$
w<\frac{1}{(B-1)^{B}} \sum_{i=0}^{N / 2}\left(\begin{array}{c}
B \\
i
\end{array}\right)(N / 2)^{i}(B-N / 2-1)^{B-i} .
$$

Given the winning probabilities of the candidates the welfare properties of the equilibria may be investigated.

\subsection{Welfare}

When voting is costly, participation implies a tradeoff between the quality of the aggregation of voters' preferences and participation costs. Higher participation decreases the probability of electing the wrong candidate (preferred by the minority), but at the same time implies higher total costs borne by society. The literature on participation offers different views on whether

\footnotetext{
${ }^{7} w$ is in fact a cdf of binomial distribution with parameters $\left(B, F\left(c^{*}\right)\right)$ evaluated at $N / 2$ and, as any binomial distribution, is decreasing in the probability of success in each Bernoulli trial $F\left(c^{*}\right)$. Intuitively, $w$ is the probability of no more than $N / 2$ success in $B$ Bernoulli trials, and it is smaller whenever success in each trial is more likely to occur.
} 
equilibrium participation in voluntary clean elections is efficient. Krishna and Morgan (2012) analyze a common value model, where voters share the same preferences for candidates but get different signals on the candidates' quality and thus may vote for different candidates; among other things, they show that when voting is costless then a voluntary voting equilibrium is fully efficient as individuals' and social objective functions are the same. Ghosal and Lockwood (2009) develop a model where voters' preferences combine both private and common values (i.e. voters prefer different candidates but also possess heterogeneous information on the common state of the world) and demonstrate that if voters vote according to their private preferences, equilibrium participation is inefficiently high whereas if they vote according to their private information, participation appears to be below the efficient level. In the model of Borgers (2004) as well as of Chakravarty, Kaplan and Myles (2010) a vote cast by a voter produces a negative externality on all other voters by decreasing their pivotal probabilities and thus expected benefits. Since this externality is not taken into account when a voter makes his participation decision, in equilibrium, participation is higher than the welfare-maximizing level. Krasa and Polborn (2009) show that if the levels of the candidates' support are ex-ante different, voting produces a positive externality: by casting a vote, a voter increases the probability that his candidate will win and, if the support levels are not equal, higher participation leads to a larger increase in the welfare of the majority than a decrease in the welfare of the minority. When this effect exceeds the extra participation costs, equilibrium participation is less than the efficient level. My model of fraudulent elections applies a similar logic to that in Krasa and Polborn (2009), though the exact mechanism through which a cast vote affects welfare differs.

First, there are two stable equilibria in this model. To see which of the two equilibria, coordination or full abstention, is more desirable from a social point of view, consider an ex-ante expected welfare evaluated at each of the equilibria. The expected utility of an A-type voter is $1-w_{B}$, where $w_{B}$ is the probability that the challenger will win. Recall that the turnout of B-type voters is a random variable. Given some voting rule $\tilde{c}$ turnout would follow a binomial distribution with parameters $B$ and $F(\tilde{c})$. Thus, the probability that the challenger will defeat the incumbent is the probability that at least $N / 2+1$ B-type voters will cast their votes:

$$
w_{B}=\sum_{i=N / 2+1}^{B}\left(\begin{array}{c}
B \\
i
\end{array}\right) F(\tilde{c})^{i}(1-F(\tilde{c}))^{B-i} .
$$

Then the expected utility of a B-type voter can be expressed as follows:

$$
\int_{0}^{\tilde{c}}\left(v_{B}+\Pi(F(\tilde{c}))-c\right) \mathrm{d} F(c)+\int_{\tilde{c}}^{c_{\max }} v_{B} \mathrm{~d} F(c)=v_{B}+\int_{0}^{\tilde{c}}(\Pi(F(\tilde{c}))-c) \mathrm{d} F(c),
$$




$$
v_{B}=\sum_{i=N / 2+1}^{B-1}\left(\begin{array}{c}
B-1 \\
i
\end{array}\right) F(\tilde{c})^{i}(1-F(\tilde{c}))^{B-i-1}
$$

Lemma 1. $w_{B}=v_{B}+\Pi(F(\tilde{c})) F(\tilde{c})$ for all $\tilde{c}$.

Proof: See Appendix.

Lemma 2. $\frac{\partial w_{B}}{\partial F(\tilde{c})}=B \Pi(F(\tilde{c}))$ for all $\tilde{c}$.

Proof: See Appendix.

The second integral in Formula (12) is the expected utility a B-type voter would gain if his cost is such that he abstains. Conditional on not casting a vote, the probability that the challenger will win is the probability that out of the other $B-1$ challenger supporters at least $N / 2+1$ participate, which is $v_{B}$. If the voter participates, which happens if his cost is below $\tilde{c}$, he incurs a cost but the probability that the challenger will win is now higher. Given that the voter participates, the challenger will win if out of the other $B-1$ voters at least $N / 2$ voters participate. The probability of this event equals

$$
\sum_{i=N / 2}^{B-1}\left(\begin{array}{c}
B-1 \\
i
\end{array}\right) F(\tilde{c})^{i}(1-F(\tilde{c}))^{B-i-1}
$$

The latter expression may be rewritten as:

$$
\sum_{i=N / 2+1}^{B-1}\left(\begin{array}{c}
B-1 \\
i
\end{array}\right) F(\tilde{c})^{i}(1-F(\tilde{c}))^{B-i-1}+\left(\begin{array}{c}
B-1 \\
N / 2
\end{array}\right) F(\tilde{c})^{N / 2}(1-F(\tilde{c}))^{B-N / 2-1}=v_{B}+\Pi(F(\tilde{c}))
$$

Thus, $\Pi(F(\tilde{c}))$ is the marginal contribution of a B-type voter to the ex-ante probability that the challenger wins, conditional on voting. Then, the voters' expected utility can be expressed as follows:

$$
W=(N-B)\left(1-w_{B}\right)+B v_{B}+B \int_{0}^{\tilde{c}}(\Pi(F(\tilde{c}))-c) \mathrm{d} F(c) .
$$

Having defined the welfare function, it is possible to compare the efficiency of full abstention equilibrium and coordination equilibrium. First, recall that in this model the voters' utility does not directly depend on the cleanness of the elections, and thus the fact that coordination equilibrium results in much lower fraud than does full abstention equilibrium, which is characterized by $100 \%$ ballot stuffing, is irrelevant for the welfare comparison. The only two features that affect voters' welfare are participation costs and the candidates' probabilities of winning. In 
coordination equilibrium, the probability of choosing candidate $\mathrm{B}$, who is the candidate preferred by a majority, is high, but at the same time there are some participation costs. Clearly, the social welfare gain from the higher probability that the challenger wins is larger if there are more B-type voters in the population. At the same time, according to Proposition 2, with the higher share of B-types the expected number of those who choose to vote decreases, implying that total participation expenditures are lower. Thus, intuitively, coordination equilibrium should welfare dominate full abstention equilibrium, at least if the share of B-types is large enough. This result is formalized in the following proposition.

Proposition 3. For any $N$ there exists $B_{0}>N / 2$ such that for any $B_{0} \leq B \leq N$ coordination equilibrium yields higher expected welfare than does full abstention equilibrium.

Proof: See the Appendix.

Further, to see that coordination equilibrium is still not socially efficient, consider social welfare as a function of some strategy $\tilde{c}$ adopted by all B-type voters:

$$
\begin{gathered}
W=(N-B)\left(1-w_{B}\right)+B v_{B}+B \int_{0}^{\tilde{c}}(\Pi(F(\tilde{c}))-c) \mathrm{d} F(c) . \\
W=(N-B)\left(1-w_{B}\right)+B v_{B}+B \Pi(F(\tilde{c})) F(\tilde{c})-B \int_{0}^{\tilde{c}} c \mathrm{~d} F(c) .
\end{gathered}
$$

Since according to Lemma $1 w_{B}=v_{B}+\Pi(F(\tilde{c})) F(\tilde{c})$, the welfare function is then simply

$$
W=(N-B)\left(1-w_{B}\right)+B w_{B}-B \int_{0}^{\tilde{c}} c \mathrm{~d} F(c)
$$

Taking the first-order condition with respect to $\tilde{c}$ we obtain:

$$
(2 B-N) \frac{\partial w_{B}}{\partial F(\tilde{c})} f(\tilde{c})-B \tilde{c} f(\tilde{c})=0
$$

After re-arranging the terms the efficiency condition takes the following form:

$$
\frac{2 B-N}{B} \frac{\partial w_{B}}{\partial F(\tilde{c})}=F^{-1}(F(\tilde{c})) .
$$

Let $c^{o}$ be the optimal voting rule, i.e. the one that satisfies condition (21). Recall the equilibrium condition:

$$
\Pi\left(F\left(c^{*}\right)\right)=F^{-1}\left(F\left(c^{*}\right)\right) .
$$

According to Lemma $2 \frac{\partial w_{B}}{\partial F(\tilde{c})}=B \Pi(F(\tilde{c}))$. Then, since $2 B-N \geq 1$ as there are strictly 
more B-type voters than A-type voters, it must be the case that for all $\tilde{c}$

$$
\frac{2 B-N}{B} \frac{\partial w_{B}}{\partial F(\tilde{c})} \geq \Pi(F(\tilde{c}))
$$

The inequality immediately implies that $c^{*} \leq c^{o}$ with equality only in the case when society consists of B-type voters only $(N=B)$, and suggests that in coordination equilibrium, participation of B-type voters is below the efficient level. Note that the statements above are valid only when the majority of voters prefer the challenger. When there are more supporters of an incumbent, the only equilibrium is full abstention which is first best, assuming that fraud is costless: the majority candidate wins with certainty at zero participation cost.

\subsection{Compulsory Voting}

Given the established inefficiency, a natural step is to find a way to increase welfare. As in any externality problem, subsidization could be one way to correct for efficiency. Another way is to introduce compulsory voting. A number of studies compare voluntary and compulsory voting from efficiency perspectives. Borgers (2004) establishes that compulsory voting is never welfare improving. Krasa and Polborn (2009) demonstrate that Borgers' result is sensitive to the assumption of equal levels of supports for the candidates, which leads to elimination of the positive externality, and thus means that any increase in participation will decrease welfare. They allow the supports to be ex-ante different and show that under certain conditions compulsory voting may be superior to voluntary voting. Ghosal and Lockwood (2004) show that Borgers' result is also sensitive to the assumption of private values of voters' preferences: once voters' preferences have both private values and common values components, compulsory voting may Pareto dominate voluntary voting. Recently, Krishna and Morgan (2012) compared compulsory and voluntary voting purely in a common values setup and show that voluntary voting welfare dominates compulsory voting when elections are large, regardless of whether voting is costless or costly.

To check whether compulsory voting may improve welfare in elections with fraud, consider the welfare function under voluntary voting evaluated at the equilibrium:

$$
W=(N-B)\left(1-w_{B}\right)+B w_{B}-B \int_{0}^{c^{*}} c \mathrm{~d} F(c) .
$$

Now compare this to the welfare function under compulsory voting:

$$
W_{c}=B-N \int_{0}^{c_{\max }} c \mathrm{~d} F(c)
$$


Note that $(N-B)\left(1-w_{B}\right)+B w_{B} \leq B$, implying that compulsory voting may be superior to voluntary, though does not have to be since $N \int_{0}^{c_{\max }} c \mathrm{~d} F(c) \geq B \int_{0}^{c^{*}} c \mathrm{~d} F(c)$. Recall that the participation rate of B-type voters in coordination equilibrium under voluntary voting is inefficiently low. Though compulsory voting results in inefficiently high participation, it still might deliver higher welfare than voluntary voting. The intuition behind this result is that compulsory voting causes the probability of electing the wrong candidate (i.e. the incumbent, who is preferred by the minority) to be zero, but at the same time requires voters to incur large participation costs. Whenever the benefit from the guarantee of choosing the majority candidate exceeds extra participation costs, compulsory voting is preferable. This is more likely to happen when there is a higher share of B-type voters. Clearly, the difference between welfare under compulsory voting and welfare under voluntary voting grows as $B$ increases and approaches $N$ :

$$
W_{c}-W=(2 B-N)\left(1-w_{B}\right)-\left[N \int_{0}^{c_{\max }} c \mathrm{~d} F(c)-B \int_{0}^{c^{*}} c \mathrm{~d} F(c)\right] .
$$

As a result, compulsory voting may deliver higher welfare than voluntary voting, and the gain from compulsory voting is likely to be larger when there are more supporters of a challenger in the population of voters. This result is very intuitive, since introducing compulsory voting eliminates the possibility of choosing the alternative preferred by the minority, and the gain from the guarantee of electing the 'correct' candidate is higher when he is preferred by a higher number of voters. Indeed, one can always construct a cost distribution such that this gain is outweighed by the costs of voters who would abstain from voting in voluntary elections. If, for example, there are voters with very high costs, which means that cdf of the cost distribution rapidly increases in the tail (to infinity in the extreme case), compulsory voting never improves welfare. However, if the cost distribution is reasonable and not extreme, then compulsory voting might be desirable.

\section{Generalized Model}

\subsection{Setup}

Consider a generalized version of the model presented above. Now, instead of assuming that the vote of a non-participant is stolen with certainty, there is an exogenously given $\alpha \in[0,1]$ that reflects the probability that the vote is stuffed in favor of the incumbent. Thus, $\alpha$ can be thought of as the incumbent's fraud capability. In addition, in contrast to the perfect fraud model where the levels of the candidates' support were known, in the generalized model only the total number of voters is known, while the exact support levels are uncertain. Instead, there is commonly 
known probability $\beta \in[0,1]$ that a voter supports candidate $\mathrm{B}$. The assumption on uncertain support levels does not have a substantial effect on the results derived further, but makes the model fully consistent with the literature on costly voting in clean elections. Once $\alpha=0$ and $\beta=0.5$, the generalized model converges to the model of clean elections with ex-ante equal support for candidates analyzed by Borgers (2004). When $\alpha=0$ and $\beta$ is arbitrary, the model is very close to the model by Krasa and Polborn $(2009)^{8}$. When $\alpha=1$ and the numbers of the incumbent's and challenger's supporters are fixed, one has the model of perfect fraud analyzed above. Finally, costs are distributed over the interval $\left[c_{\min }, c_{\max }\right]$ where $c_{\min } \geq 0$.

\subsection{Analysis}

Consider a B-type voter. Suppose that all other B-type voters adopt voting strategy $c_{B}$, i.e. a B-type voter votes if his voting costs are below $c_{B}$ and abstains otherwise. Similarly, suppose A-type voters adopt strategy $c_{A}$. Then the probability that a randomly picked voter votes is $F\left(c_{B}\right)$ and $F\left(c_{A}\right)$ for B-types and A-types respectively.

The probability that there are $a$ incumbent supporters among other $N-1$ voters is

$$
P_{a}^{N-1}=\left(\begin{array}{c}
N-1 \\
a
\end{array}\right)(1-\beta)^{a} \beta^{N-a-1}
$$

The probability that $k$ of them participate in elections is

$$
P_{k}^{a}=\left(\begin{array}{l}
a \\
k
\end{array}\right) F\left(c_{A}\right)^{k}\left(1-F\left(c_{A}\right)\right)^{a-k}
$$

The probability that $m$ out of another $N-a-1$ B-type voters participate is

$$
P_{m}^{N-a-1}=\left(\begin{array}{c}
N-a-1 \\
m
\end{array}\right) F\left(c_{B}\right)^{m}\left(1-F\left(c_{B}\right)\right)^{N-a-m-1} .
$$

A B-type voter is pivotal in two cases. First, if the number of stolen votes is such that the number of votes for each candidate is equal, and second, if the challenger leads by one vote and the voter's ballot is stolen if he abstains. If $x$ votes are stolen, the incumbent gets $x+k$ and the challenger gets $m$ votes. Thus, given $a, k$ and $m$, a B-type voter is pivotal if and only if $x=m-k$ or $x=m-k-1$. The probability of this event is

$$
P_{m-k}^{N-k-m-1}+\alpha P_{m-k-1}^{N-k-m-1}
$$

${ }^{8}$ Borgers (2004) and Krasa and Polborn (2009) assume that a tie is resolved with the toss of a coin, while the presented model assumes that the tie is resolved in favor of the incumbent. 
where $P_{m-k}^{N-k-m-1}=\left(\begin{array}{c}N-k-m-1 \\ m-k\end{array}\right) \alpha^{m-k}(1-\alpha)^{N-2 m-1}$.

The probability that $a$ out of $N-1$ voters support the incumbent, $k$ out of these $a$ Asupporters participate, $m$ out of $N-a-1$ challenger supporters participate, and $m-k$ or $m-k+1$ votes out of $N-k-m-1$ non-participants' votes are stolen is then:

$$
P_{B}\left(a, k, m, c_{A}, c_{B}\right)=P_{a}^{N-1} P_{k}^{a} P_{m}^{N-a-1}\left(P_{m-k}^{N-k-m-1}+\alpha P_{m-k-1}^{N-k-m-1}\right) .
$$

Finally, the probability that a B-type voter is pivotal is a function of voting strategies $c_{A}$ and $c_{B}$ adopted by all the A-type and all the B-type voters respectively:

$$
\Pi_{B}\left(c_{A}, c_{B}\right)=\sum_{a=1}^{N-1} \sum_{k=0}^{a} \sum_{m=k-1}^{B-1} P_{B}\left(a, k, m, c_{A}, c_{B}\right) .
$$

Similarly, one can construct a pivotal probability function for an A-type voter:

$$
\Pi_{A}\left(c_{A}, c_{B}\right)=(1-\alpha) \sum_{a=1}^{N-1} \sum_{k=0}^{a-1} \sum_{m=k-1}^{B} P_{A}\left(a, k, m, c_{A}, c_{B}\right)
$$

where $P_{A}\left(a, k, m, c_{A}, c_{B}\right)=P_{a}^{N-1} P_{k}^{a} P_{m}^{N-a-1} P_{m-k-1}^{N-k-m-1}$.

Note, that there is a $(1-\alpha)$ term in the pivotal probability function for incumbent supporters: an A-type voter will be pivotal only if his vote is not stolen in case of abstention; otherwise his participation decision will not change the outcome.

Symmetric equilibrium is characterized by a pair $\left(c_{A}, c_{B}\right)$ such that all A-type voters with costs below $c_{A}$ and all B-type voters with costs below $c_{B}$ participate, and the others abstain. Equilibrium values of $c_{A}$ and $c_{B}$ are the solution for the following system of equations:

$$
\begin{aligned}
& \Pi_{A}\left(c_{A}, c_{B}\right) \geq c_{A}, \\
& \Pi_{B}\left(c_{A}, c_{B}\right) \geq c_{B},
\end{aligned}
$$

with equalities when $c_{A}<c_{\max }$ and $c_{B}<c_{\max }$ respectively.

If one defines a function $L:\left[c_{\min }, c_{\max }\right]^{2} \rightarrow\left[c_{\min }, c_{\max }\right]^{2}$ as:

$$
L\left(c_{A}, c_{B}\right)=\left(\max \left\{\min \left\{\Pi_{A}\left(c_{A}, c_{B}\right), c_{\max }\right\}, c_{\min }\right\}, \max \left\{\min \left\{\Pi_{B}\left(c_{A}, c_{B}\right), c_{\max }\right\}, c_{\min }\right\}\right),
$$

then Brouwer's fixed point theorem will imply the existence of equilibrium.

As in the case of the perfect fraud model, equilibrium voting rules $\left(c_{A}, c_{B}\right)$ are one-toone matched to the pair $\left(F\left(c_{A}\right), F\left(c_{B}\right)\right)$ - equilibrium participation of the incumbent's and the challenger's supporters respectively. Figure 3 demonstrates an equilibrium for the following 
values of parameters: $N=25, \beta=0.7, \alpha=0.3$, costs are distributed uniformly over the interval $[0.01,0.1]$. The red (darkest) surface is the net expected benefit of a B-type voter as a function of $F\left(c_{A}\right), F\left(c_{B}\right): \Pi_{B}\left(F\left(c_{A}\right), F\left(c_{B}\right)\right)-F^{-1}\left(F\left(c_{B}\right)\right)$. Similarly, the blue surface is the net expected benefit of an A-type voter: $\Pi_{A}\left(F\left(c_{A}\right), F\left(c_{B}\right)\right)-F^{-1}\left(F\left(c_{A}\right)\right)$. The yellow (lightest) surface is a zero-plane. Thus, a point where all three surfaces intersect would be an equilibrium.

Figure 3: Equilibrium in the generalized model.

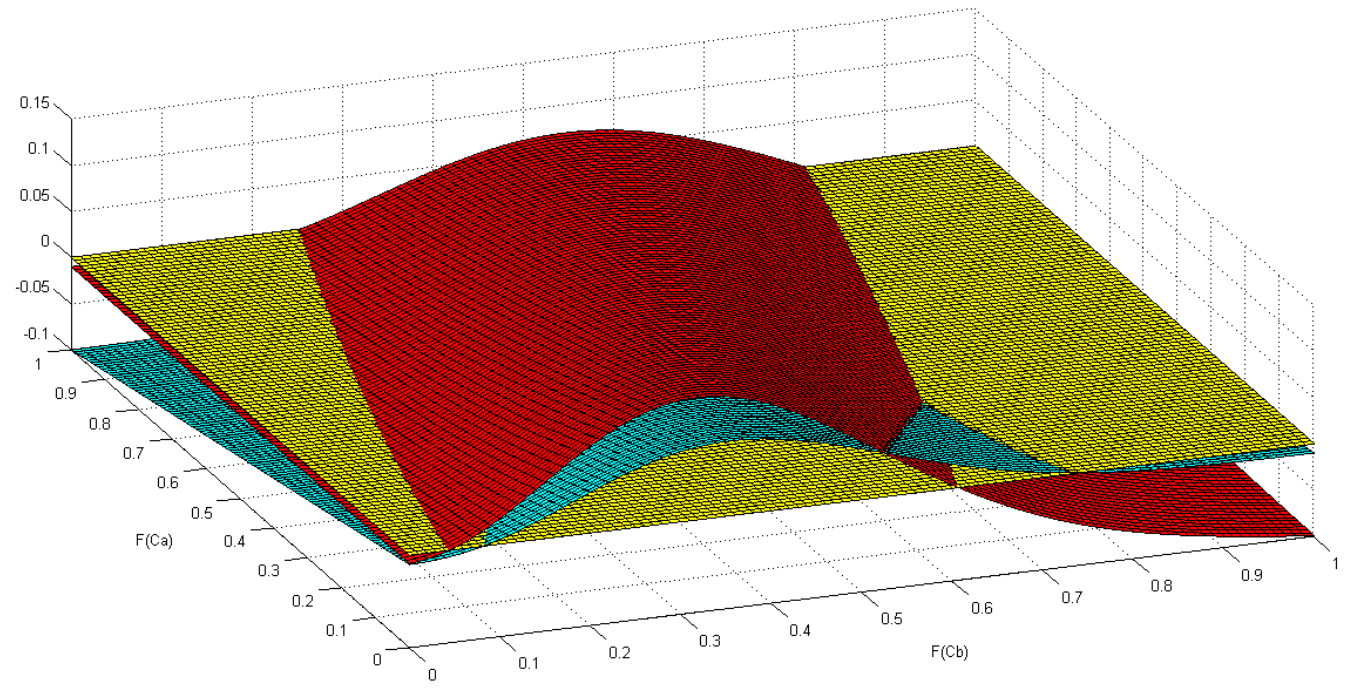

There is one such point on the figure above: $(0.27,0.63)$. However, there are two more equilibria here. First $(0,0)$ is an equilibrium (stable) because for both types of voters net expected benefits are negative at this point, and thus no voter has any incentive to vote. Second, $(0,0.05)$ is an equilibrium (unstable) since the net expected benefit of A-type voters is negative, so they do not vote, while B-types' net expected benefit is exactly 0 at this point.

Obtaining a closed-form solution and even characterizing equilibria for the generalized model is quite challenging. However, numerical simulations provide a number of consistent observations about the equilibria and their properties. As in the case of perfect fraud model, I focus on stable coordination equilibrium. The first question is how changes in fraud capability $\alpha$ affect equilibrium. Consider a simple numerical example with just two voters both supporting challenger with probability 1.

Example 1. $N=2, \beta=1$, costs are distributed uniformly over $\left[c_{\min }, c_{\max }\right]$, where $0<c_{\min }<1$. A voter is pivotal if either another voter participates and the vote of the first voter is stolen in case of abstention, or another voter abstains and his vote is not stolen. Thus, equilibrium is given by the following equation:

$$
\alpha F\left(c_{B}\right)+(1-\alpha)\left(1-F\left(c_{B}\right)\right)=\left(c_{\max }-c_{\min }\right) F\left(c_{B}\right)+c_{\min } .
$$


The solution is then $F\left(c_{B}^{*}\right)=\frac{1-\alpha+c_{\min }}{c_{\max }-c_{\min }-2 \alpha+1}$, which is increasing in $\alpha$.

Note that if the second voter always abstains, the expected benefit of the first voter is $(1-\alpha)$. Whenever this benefit is less than the minimal possible cost of voting $c_{\text {min }}$, i.e. when $\alpha>1-c_{\text {min }}$, the first voter also abstains, and thus $F\left(c_{B}^{*}\right)=0$ constitutes another equilibrium.

In the example above, fraud capability $\alpha$ leads to an increase in the equilibrium participation of B-type voters, conditional on coordination. Simulations of the model for a higher number of voters provide similar results: an increase in $\alpha$ decreases the participation incentives of the incumbent's supporters and increases the participation incentives of the challenger's supporters. To understand how equilibrium participation rates change in response to an increase in $\alpha$ consider Figure 4, which displays two-dimensional representation of the equilibrium in the generalized model with the following values of the parameters: $N=25, \beta=0.7$, costs are distributed uniformly over the interval $[0.01,0.1]$. In Figure 4 the blue (dark) curve is the solution $c_{A}\left(c_{B}\right)$ of the first equation of system (34) and a red (light) curve is the solution of the second equation. The graph presents the solutions for three distinct values of $\alpha$ : 0.3, 0.5 and 0.7. Equilibrium is determined by the intersection of red and blue curves of the same type which correspond to the same value of $\alpha$ (the blue curve with the highest maximum corresponds to $\alpha=0.3$, the blue curve with the lowest maximum correspond to $\alpha=0.7$ ).

Figure 4: Equilibrium for different values of $\alpha$.

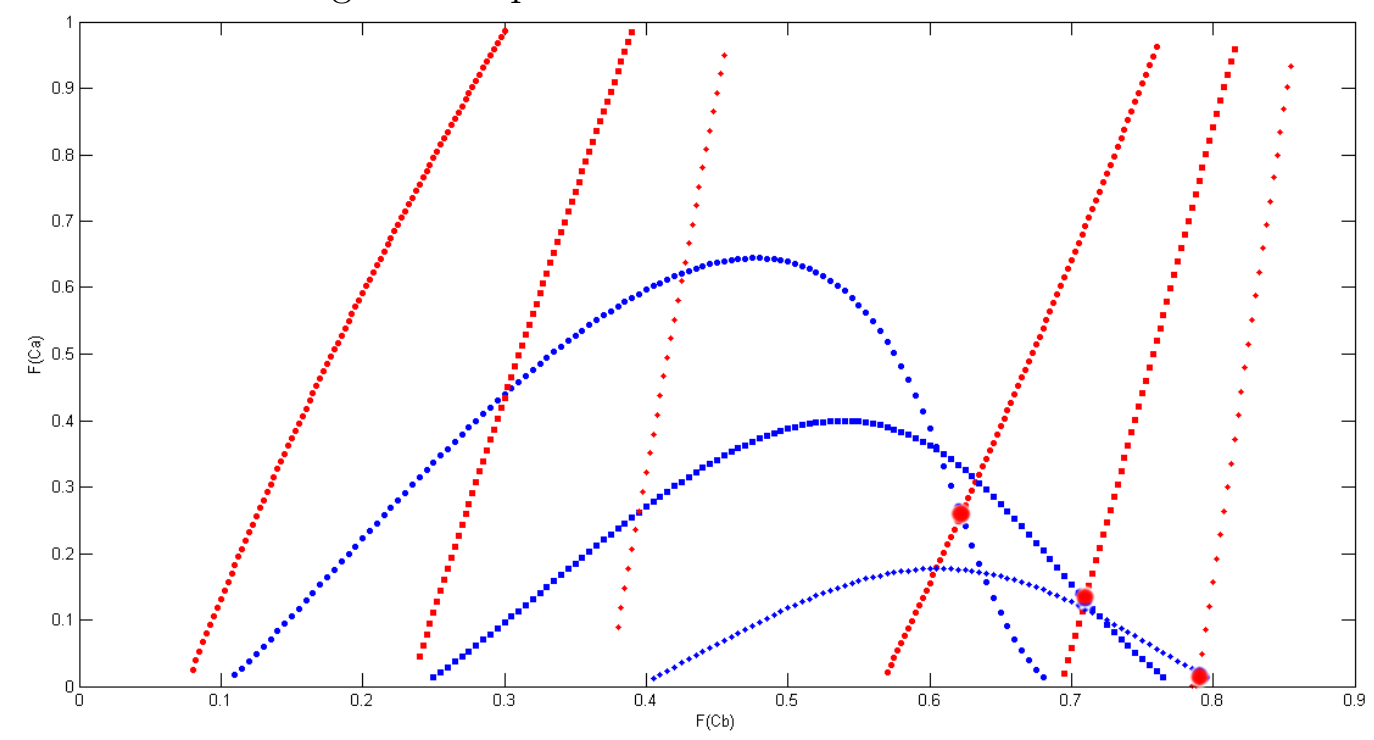

This result is robust to different choices of the model's parameters. Figure 5 shows how changes in $\alpha$ affect participation of the incumbent's supporters (blue curve) and the challenger's supporters (red curve) for $N=25, \beta=0.7$, costs distributed uniformly over the interval $[0.01,0.1]$. 
Figure 5: Coordination equilibrium participation of A-supporters (downward sloping) and Bsupporters (upward sloping) as a function of fraud capability

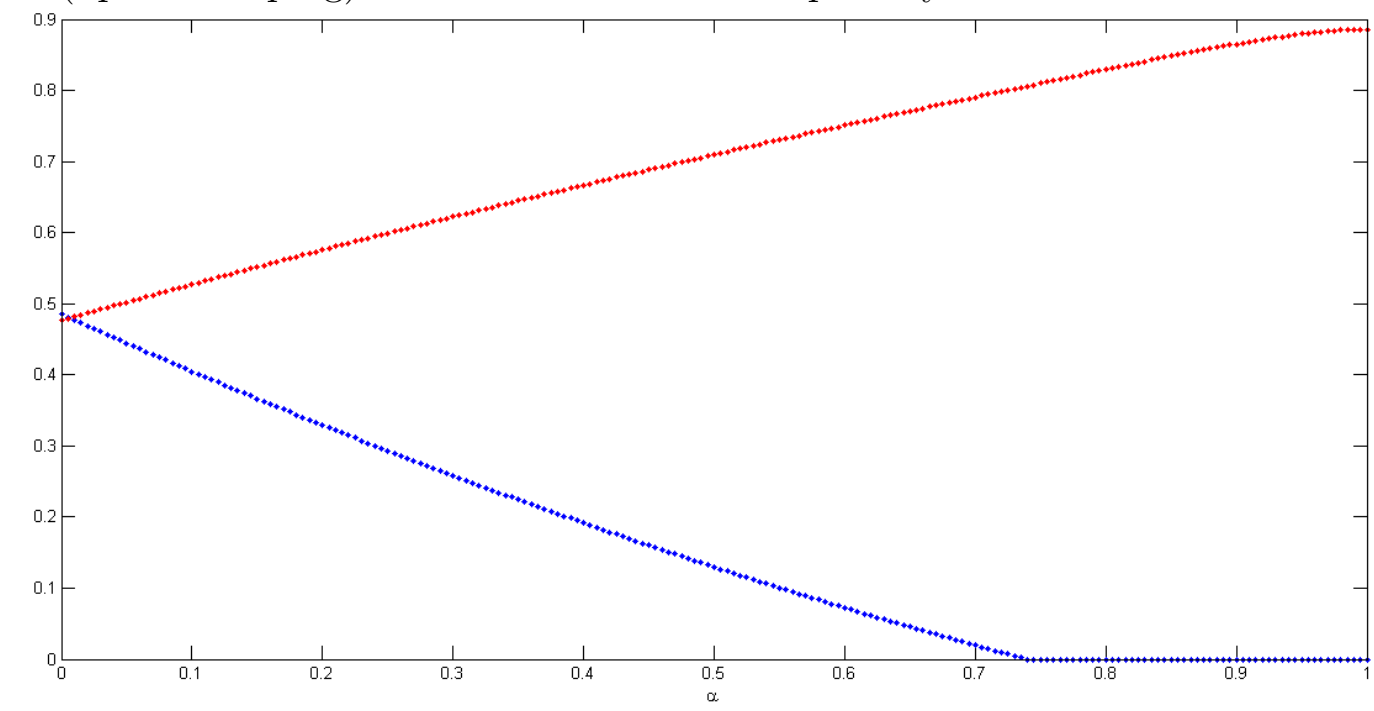

Figure 5 shows that the participation incentives of A-type voters decrease with higher $\alpha$. The intuition is straightforward: the higher the incumbent's fraud capability, the more likely the incumbent will steal an A-type's vote if the voter abstains and avoids cost, the less incentive to participate the voter has. The effect of an increase in $\alpha$ on coordination equilibrium participation of the B-types is the opposite. Higher fraud capability implies that higher participation among B-types is needed to maintain sufficiently high pivotal probabilities. Note that though higher $\alpha$ leads to higher participation of the challenger's supporters in coordination equilibrium, at the same time it requires more people to coordinate in order to achieve this equilibrium.

Further note that when elections are perfectly fraudulent, there are two stable equilibria: full abstention equilibrium and coordination equilibrium. In clean elections, as shown by Borgers (2004) and Krasa and Polborn (2009), there is unique equilibrium. Thus, it must be the case that sufficiently large fraud capability leads to the emergence of a bad full abstention equilibrium. This observation is formalized in Proposition 4.

Proposition 4. For given values of $N$ and $\beta$, and cost distribution $F$, there is a unique value $\alpha_{0}$ such that for any $\alpha \geq \alpha_{0}$ full abstention is an equilibrium, and for any $\alpha<\alpha_{0}$ it is not.

Proof: See Appendix.

The proposition is very intuitive: when fraud capability is low, full abstention cannot be an equilibrium because a single voter has a good chance of influencing the outcome of elections by deviating and participating. But when fraud capability is high, implying that there is a high probability that the vote of a non-participant will be stolen, participating when all the others 
abstain is unlikely to be profitable as there is a high probability that a sufficient number of votes will be stuffed in favor of the incumbent, and thus deviation from abstention will not change the outcome of elections.

\subsection{Endogenous Fraud}

Suppose now that $\alpha$ is no longer exogenous, but rather the incumbent is free to choose it. Anticipating the response of the voters to any level of fraud capability $\alpha$, a rational incumbent would choose an $\alpha$ that maximizes his probability of winning the election. Assume for simplicity that fraud is costless. It might seem at first glance that in this case the incumbent should choose maximum possible fraud capability, which is $\alpha=1$. However an increase in fraud capability has several effects. First, higher $\alpha$, other things being equal, implies a higher number of stuffed ballots and thus a higher probability that the incumbent wins. But changes in $\alpha$ also affect the participation of voters. Specifically, as stated above, a higher $\alpha$ has a deterrent effect on the participation of the incumbent's supporters and a stimulating effect on participation of the challenger's supporters (conditional on the fact that coordination equilibrium is achieved), which together lead to a decrease in the probability that the incumbent will win. Thus, the resulting effect of an increase in $\alpha$ on the probability that the incumbent wins depends on which of the two effects dominates. To illustrate this intuition, consider an example.

Example 2. Suppose there are just three voters, and assume for simplicity that supports are known: one voter is A-type and the other two voters are B-type; costs are distributed uniformly over $[0,0.5]$. In clean elections, the A-type voter is pivotal if and only if one out of two B-types participates. A B-type voter may be pivotal in two cases, either if another B-type and A-type both abstain or both participate. Thus, pivotal probabilities as functions of voting strategies $c_{A}$ and $c_{B}$ are:

$$
\begin{array}{r}
\Pi_{A}=2 F\left(c_{B}\right)\left(1-F\left(c_{B}\right)\right), \\
\Pi_{B}=\left(1-F\left(c_{A}\right)\right)\left(1-F\left(c_{B}\right)\right)+F\left(c_{A}\right) F\left(c_{B}\right) .
\end{array}
$$

Then equilibrium is a solution of the following system:

$$
\begin{aligned}
4 c_{B}\left(1-2 c_{B}\right) & =c_{A}, \\
\left(1-2 c_{A}\right)\left(1-2 c_{B}\right)+4 c_{A} c_{B} & =c_{B} .
\end{aligned}
$$

This system has a unique solution, which is approximately $\left(c_{A}{ }^{*}, c_{B}{ }^{*}\right)=(0.21,0.44)$. The incumbent may win clean elections in two cases: when all three voters abstain, or when the A- 
type voter participates and at least one B-type voter abstains. Given equilibrium participation strategies $\left(c_{A}{ }^{*}, c_{B}{ }^{*}\right)$, the probability that the incumbent wins is

$$
w_{A}=\left(1-F\left(c_{A}^{*}\right)\right)\left(1-F\left(c_{B}^{*}\right)\right)^{2}+F\left(c_{A}^{*}\right)\left(1-F\left(c_{B}^{*}\right)^{2}\right)=0.103 .
$$

If elections are perfectly fraudulent, the A-type always abstains, and a B-type is pivotal if and only if another B-type voter participates. Thus, equilibrium is determined by $F\left(c_{B}\right)=c_{B}$. Clearly, one equilibrium is $c_{B}{ }^{*}=0$ which corresponds to full abstention. However, $c_{B}{ }^{*}=0.5$, which corresponds to full participation among B-types, is also an equilibrium, as in this case expected benefit $F(0.5)=1$ always exceeds costs. In full abstention equilibrium the incumbent always wins, while in coordination equilibrium he inevitably loses. Thus, if the incumbent can choose whether to hold clean elections or stuff the ballot box perfectly, clean elections would be preferable if the challenger's supporters coordinate well, even if fraud is costless

Figure 6 shows the incumbent's winning probability in coordination equilibrium as a function of $\alpha$ for $N=25, \beta=0.7$, and voting costs distributed uniformly over the interval [0.01, 0.1]. From Figure 6 it is clear that that maximum feasible fraud level is not necessarily optimal.

Figure 6: The incumbent's winning probability as a function of fraud capability.

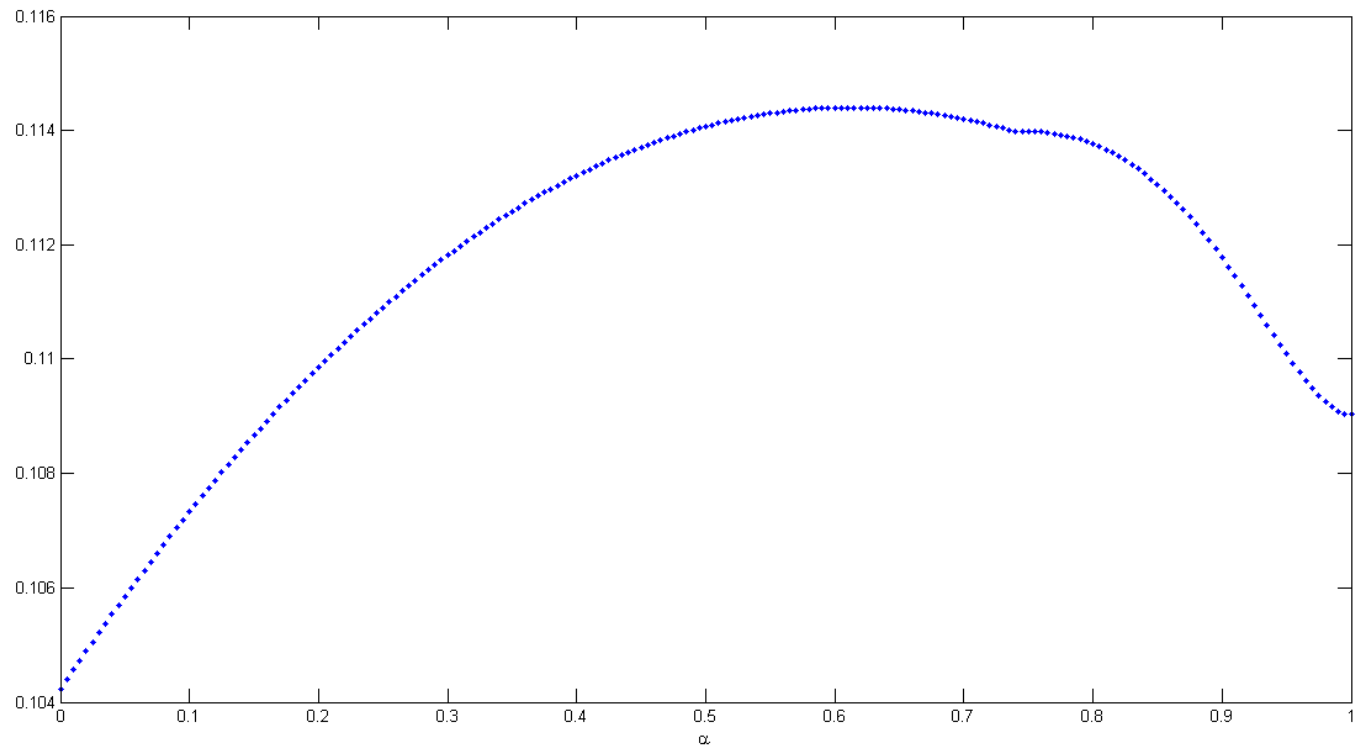

Further, recall Proposition 4 which states that a threshold value exists, such that for all $\alpha$ above this value equilibrium with full abstention exists, and for all $\alpha$ below this value it does not exist. From the incumbent's point of view, full abstention equilibrium is the first best as it guarantees the incumbent's victory with certainty. For the parameters used to construct Figure 6 the threshold equals $\alpha_{0}=0.22$. 
Further, the winning probability achieves its maximum for some $\alpha^{*}$. Note that a higher value of $\alpha$ implies that the participation rate of the challenger's supporters in coordination equilibrium is higher, which in turn means that solving the collective action problem is more difficult and thus achieving coordination equilibrium is less likely. Ultimately, when choosing fraud level, the incumbent faces a triple tradeoff: costs of fraud, likelihood of coordination among the challenger's supporters, and winning probability given that coordination is achieved. If the incumbent is strong enough to deter coordination of the opposition's supporters, he would probably choose a low level of fraud close to $\alpha_{0}$, while a weak incumbent would prefer a high level fraud close to $\alpha^{*}$, which makes coordination harder and provides relatively high chances of winning even if this coordination is achieved.

When fraud capacity $\alpha$ is considered as an endogenous variable which is subject to the incumbent's choice, then given the timing of the model, one may argue that there is a commitment problem if $\alpha$ is easily adjustable. Since, first, the incumbent sets $\alpha$, then voters make their participation decisions, and only then fraud is realized, the incumbent would always benefit by increasing $\alpha$ from the announced level once voters have made their decisions. If this is the case, then the discussion on optimal $\alpha$ should be thought of as comparative statics with respect to fraud capability rather than the rational incumbent's choice. However, in reality, targeted fraud level is unlikely to be such an easily adjustable variable as it is the result of a comprehensive rigging process which takes place not only on election day, but begins also long before. In this case, though the incumbent does not commit to maintaining the announced level of $\alpha$, his ability to adjust it at the last moment is very limited.

\section{Discussion and Empirical Evidence}

The presented model generates a number of predictions about voters' and candidates' behavior as well as outcomes in fraudulent elections. It would indeed be valuable to empirically test the validity of these predictions with real electoral data. The problem is that the main results involve the incumbent's fraud capability: its optimal choice, influence on the participation incentives of different groups of voters, and effect on the winning probabilities of the candidates, while the extant, though relatively limited, empirical literature on fraudulent elections primarily studies ex-post realized fraud rather than the ex-ante potential of an incumbent to steal votes. The obvious reason for this is that even ex-post fraud is not an easily measurable variable, so fraud capability seems considerably more challenging to measure or even proxy. Though the main results of the model cannot be easily tested due to this problem, there are still several empirical observations about fraudulent elections that may be used to verify the consistency of the model. Specifically, the model explains two main empirical observations about fraudulent elections: the 
negative effect of fraud on turnout, and the positive relationship between fraud and victory margin.

A number of survey-based and empirical studies have shown that voters are less likely to participate in elections if they expect fraud. This result was established by McCann and Domingues (1998), who utilized Mexican survey data and found opposition supporters to be more likely to abstain when expectations of fraud are high. The finding was later confirmed by Hiskey and Bowler (2005) who also employed Mexican data to study the impact of procedural fairness on citizens' political engagement. Among other results, they find that individuals who believe that elections are clean are more likely to participate. More recently, Birsch (2010) empirically analyzed cross-country electoral survey data from both new and established democracies and shows that ex-ante fairness of elections is positively related to turnout. She finds that, controlling for a variety of individual- and election-level characteristics, perceived electoral integrity has a strong positive effect on the propensity to vote. Similarly, Landry, Davis and Wang (2010) study local elections in China and conclude that when the race is close, voters perceive elections as fair and are more likely to vote. In contrast to the survey-based research, Simpser (2012) explores Mexican electoral data to assess the relationship between voters' participation incentives and fraud. Using variation in fraud and turnout across Mexican states, and explicitly distinguishing between reported and true turnout, he finds that electoral manipulations discourage voter participation.

The negative relationship between fraud perception and turnout is generally explained by the low incentives of the electorate to participate in costly voting if elections lack competitiveness. Low incentives are assumed to be the result of either direct disutility from participating in corrupt elections (e.g. Simpser, 2008) or from low likelihood of a vote to be pivotal, which in turn comes from a lack of competition (e.g. Birsch, 2010). Though the idea that in fraudulent elections a single voter is less likely to be pivotal, which decreases participation incentives, has been pointed out in the literature, the mechanism behind the relationship between fraud and pivotal probabilities has not been explored in any depth. Indeed, this relationship is not monotonic: fraud can both decrease and increase the competitiveness of elections. It may give a corrupt candidate an overwhelming advantage, but it can also create a chance for an incumbent with low support to make the race competitive. Hence, the effect of fraud on pivotal probabilities is not entirely straightforward and thus the mechanism through which fraud affects participation incentives requires a consistent explanation. This paper provides such an explanation and sheds light on the nature of the relationship between fraud and turnout. In simple terms, the explanation is that the observed correlation is not the result of a direct negative causal effect of fraud on participation, but rather an equilibrium outcome of an electoral game.

The model of elections with ballot stuffing predicts the existence of two stable equilibria. 
In full abstention equilibrium, none of the voters participate and the incumbent stuffs a lot of ballots. The expectation is that the number of stuffed ballots equals $\alpha N$ if the incumbent's fraud capability is $\alpha$. In coordination equilibrium, positive shares of both A-type and B-type voters participate, and thus there is less space for ballot stuffing than in full abstention equilibrium. These two equilibria generate the correlation between fraud and turnout observed in real data: higher fraud goes hand-in-hand with lower participation.

This result might seem trivial since the ex-post amount of ballot stuffing is simply a linear function of turnout: the number of stuffed ballots always equals the difference between the total number of voters and the number of participants, multiplied by $\alpha$. This is true, but the key point here is that the number of participants is not a decreasing function of the number of stuffed ballots or vice versa: the negative correlation between fraud and turnout is generated not by a mechanical linear relationship between turnout and the amount of stuffed ballots, but rather by the negatively related values of turnout and fraud which constitute equilibria. The key point is that the incumbent needs to maintain low participation to guarantee he will win. The only way to ensure this is to commit extensive fraud: if voters fail to coordinate, then their participation incentives are low, given extensive fraud commitment. But extensive fraud is possible only when a lot of voters (all of them in the model) abstain, since ballot stuffing uses residual turnout to transform unused ballots into votes. This situation corresponds to the full abstention equilibrium. Alternatively, if voters coordinate and vote, then there is not much opportunity for ballot stuffing, and the extent of fraud is relatively moderate, which in turn provides sufficient incentives for voters to coordinate. This corresponds to coordination equilibrium. Together, full abstention and coordination equilibria generate a negative fraud-turnout relationship, implying that low (high) turnout is not just a consequence of high (low) fraud, but rather low (high) turnout and high (low) fraud are simultaneously determined equilibrium outcomes.

Similar logic lies behind the explanation for the second empirical observation about fraudulent elections, which relates integrity, victory margin, and fraud excessiveness. Simpser (2008) collects and analyzes a dataset of about 400 executive elections held worldwide between 1990 and 2007, in which multiple candidates were allowed to run, to establish a positive relationship between electoral fraud and victory margin. For each election he uses a variety of available sources ranging from observers' reports and newspaper articles to academic research and poll data to mark the election as either clean or corrupt. The main finding of the analysis is that in fraudulent elections, a high victory margin is observed far more frequently than in clean elections: in about $40 \%$ of elections marked as corrupt the victory margin exceeds $40 \%$. This result generally holds for the analysis of alternative datasets on fraudulent elections such as the Database of Political Institutions by the World Bank (Beck, Clarke, Groff, Keefer, Walsh, 2001) as well as the one collected by Pastor (1999). 
From this observation it follows that corrupt politicians often commit excessive electoral fraud. In part, this could arise from the incumbent's uncertainty about the election outcome. If the candidate is risk averse and the costs of fraud are low relative to the stakes of re-election, such uncertainty could provide incentives for excessive fraud. Simpser (2008) explains fraud excessiveness using a two-period voting game where a high victory margin in the first period discourages the participation of opposition supporters in the second period, creating incentives for the incumbent to excessively commit fraud. My model of elections with ballot stuffing suggests an alternative and simpler explanation using a logic similar to that of fraud-turnout correlation. Full abstention equilibrium is characterized by extensive fraud and a $100 \%$ victory margin, which is far beyond the level needed to guarantee the incumbent's victory. In contrast, coordination equilibrium implies that elections are relatively clean ex-post and the winning candidate has a reasonable victory margin. Again, the fact that relatively clean elections correspond to a reasonable victory margin, while fraudulent elections are associated with an extremely large margin, comes not from the causal effect of fraud on victory margin, but arises as an equilibrium outcome.

\section{Conclusion}

In this paper I explore the mechanism through which electoral fraud affects the decisions of voters to participate in elections and, thus, social welfare. I analyze a pivotal voter model of elections with costly participation, where the incumbent can stuff the ballot box and voters decide whether to participate in elections or abstain based on a comparison of their subjective probability that their vote will be pivotal with individual-specific participation costs. I show that when a majority of voters support the challenger, two stable equilibria may exist: full abstention equilibrium, where the incumbent wins with certainty and which exists only if the incumbent's capability to stuff a ballot box is sufficiently strong, and a more efficient coordination equilibrium, where a substantial share of a challenger's supporters vote and the probability the incumbent will be defeated is large. I find that participation in the coordination equilibrium is still inefficiently low, since voters do not take into account the positive externality they produce on other voters when participating. Each vote cast by a challenger's supporter increases the probability of the incumbent's defeat, and if the incumbent is supported by a minority of voters, this has a positive effect on the overall welfare of voters. Thus subsidization, and in some cases even the introduction of compulsory voting, may improve efficiency. I then show that higher capability of the incumbent to stuff a ballot box discourages the participation of his own supporters and creates coordination incentives for a challenger's supporters. Hence, fraud does not always benefit the incumbent even when it is costless. Additionally, the model simultaneously explains two empirical observations 
about fraudulent elections: the positive relationship between fraud and victory margin, and the negative effect of fraud on turnout. 


\section{Appendix A}

Proof of Proposition 1. 1. Suppose coordination equilibrium exists for some parameter set $\left(N_{0}, B_{0}, F_{0}(c)\right)$, and one decreases population size: $N_{1}=N_{0}-t$. If the support ratio is fixed, then $\frac{B_{0}}{N_{0}-B_{0}}=\frac{B_{1}}{N_{1}-B_{1}}$, implying $B_{1}=B_{0} \frac{N_{1}}{N_{0}}=B_{0}-\frac{B_{0} t}{N_{0}}$. Note that both $t / 2$ and $\frac{B_{0} t}{N_{0}}$ must be integers. Denote:

$$
\begin{gathered}
\Pi_{0}(p)=\left(\begin{array}{c}
B_{0}-1 \\
N_{0} / 2
\end{array}\right) p^{N_{0} / 2}(1-p)^{B_{0}-N_{0} / 2-1} \\
\Pi_{1}(p)=\left(\begin{array}{c}
B_{0}-\frac{B_{0} t}{N_{0}}-1 \\
N_{0} / 2-t / 2
\end{array}\right) p^{N_{0} / 2-t / 2}(1-p)^{B_{0}-\frac{B_{0} t}{N_{0}}-N_{0} / 2+t / 2-1} .
\end{gathered}
$$

Lemma 3. $\Pi_{0}(p) \leq \Pi_{1}(p)$ for all $p$. Proof: See Appendix B.

Lemma 3 immediately implies the result: if coordination equilibrium exist for parameters $\left(N_{0}, B_{0}, F_{0}(c)\right)$ then $\exists \bar{p} \in(0,1]$ such that $F_{0}{ }^{-1}(\bar{p}) \leq \Pi_{0}(\bar{p}) \leq \Pi_{1}(\bar{p})$ and thus, equilibrium exists for parameters $\left(N_{1}, B_{1}, F_{0}(c)\right)$.

2. Suppose coordination equilibrium exists for some cost distribution $F_{0}$. Thus, $\exists \bar{p} \in(0,1]$ such that $F_{0}^{-1}(\bar{p}) \leq \Pi(\bar{p})$. Any $F$ which is first order stochastically dominated by $F_{0}$ satisfies $F(c) \geq F_{0}(c)$ for all $c$. Hence, $F^{-1}(p) \leq F_{0}{ }^{-1}(p)$ for all $p \in[0,1]$, including $\bar{p}$. From $F^{-1}(\bar{p}) \leq F_{0}{ }^{-1}(\bar{p}) \leq \Pi(\bar{p})$ existence of equilibrium for cost distribution $\mathrm{F}$ follows immediately.

3. Coordination equilibrium exists whenever $\Pi\left(\frac{N / 2}{B-1}\right) \geq F^{-1}\left(\frac{N / 2}{B-1}\right)$. Because $\Pi(p)$ is continuous, and for any $B$ and $N$ such that $N / 2+1 \leq B \leq N$ its maximum $\Pi\left(\frac{N / 2}{B-1}\right)>0$, there always exists some $x$ such that $\Pi\left(\frac{N / 2}{B-1}\right)>x>0$. Let $\bar{x}=\sup \left\{x \mid 0 \leq x<\Pi\left(\frac{N / 2}{B-1}\right)\right\}$. Then, any $F$ such that $F^{-1}\left(\frac{N / 2}{B-1}\right)=\bar{x}$ satisfies $\Pi\left(\frac{N / 2}{B-1}\right) \geq F^{-1}\left(\frac{N / 2}{B-1}\right)$, which guarantees existence of coordination equilibrium.

Proof of Proposition 2. 1. Let $p^{*}$ be an equilibrium participation level and $p^{t}$ an enforcement threshold under some $N, B$ and $F$, while $\tilde{p}$ is an equilibrium participation level and $\tilde{p}^{t}$ is an enforcement threshold under $N, B+1$ and $F$. Then, $p^{*}$ is an argument of an intersection point between increasing function $F^{-1}(p)$ and decreasing part of $\Pi(p, B)$, i.e. for $p>\frac{N / 2}{B-1}$. Likewise, $\tilde{p}$ is an argument of an intersection point between the same $F^{-1}(p)$ and decreasing 
part of $\Pi(p, B+1)$, i.e. for $p>\frac{N / 2}{B}$. Thus, to prove that $p^{*}>\tilde{p}$ it is sufficient to show that $\Pi(p, B)>\Pi(p, B+1)$ for $p>\frac{N / 2}{B-1}$. It is easy to see that $\Pi(p, B+1)-\Pi(p, B)$ is negative if $p>\frac{N / 2}{B}$ and thus for any $p>\frac{N / 2}{B-1}$ :

$$
\begin{gathered}
\Pi(p, B+1)-\Pi(p, B)=\left(\begin{array}{c}
B \\
N / 2
\end{array}\right) p^{N / 2}(1-p)^{B-N / 2}-\left(\begin{array}{c}
B-1 \\
N / 2
\end{array}\right) p^{N / 2}(1-p)^{B-N / 2-1}, \\
\Pi(p, B+1)-\Pi(p, B)=\left(\begin{array}{c}
B-1 \\
N / 2
\end{array}\right) p^{N / 2}(1-p)^{B-N / 2-1}\left[\frac{B}{B-N / 2}(1-p)-1\right] .
\end{gathered}
$$

Similarly, $p^{t}$ is an argument of an intersection point between non-decreasing function $F^{-1}(p)$ and increasing part of $\Pi(p, B)$, i.e. for $p<\frac{N / 2}{B-1}$. Likewise, $\tilde{p}^{t}$ is an argument of an intersection point between the same $F^{-1}(p)$ and increasing part of $\Pi(p, B+1)$, i.e. for $p<\frac{N / 2}{B}$. Since $\Pi(p, B)<\Pi(p, B+1)$ for $p<\frac{N / 2}{B}$, it follows that $p^{t}>\tilde{p}^{t}$.

2. Let population size decrease from some $N_{0}$ to $N_{1}<N_{0}$ keeping the support ratio $\frac{N_{0}-B_{0}}{B_{0}}$ fixed. Let $p^{*}$ and $p^{t}$ be equilibrium participation level and threshold under $N_{0}$, while $\tilde{p}$ and $\tilde{p}^{t}$ are equilibrium participation level and threshold under $N_{1}$. Let $N_{1}=N_{0}-t$. To keep the support ratio fixed $B_{1}$ should be equal to $B_{0}-\frac{B_{0} t}{N_{0}}$, and $t / 2$ as well as $\frac{B_{0} t}{N_{0}}$ must be an integer. Denote

$$
\begin{gathered}
\Pi_{0}(p)=\left(\begin{array}{c}
B_{0}-1 \\
N_{0} / 2
\end{array}\right) p^{N_{0} / 2}(1-p)^{B_{0}-N_{0} / 2-1} \\
\Pi_{1}(p)=\left(\begin{array}{c}
B_{0}-\frac{B_{0} t}{N_{0}}-1 \\
N_{0} / 2-t / 2
\end{array}\right) p^{N_{0} / 2-t / 2}(1-p)^{B_{0}-\frac{B_{0} t}{N_{0}}-N_{0} / 2+t / 2-1} .
\end{gathered}
$$

As shown in the proof of Proposition $1 \Pi\left(p, B_{0}\right) \leq \Pi\left(p, B_{1}\right)$ for all $p$, where $B_{1}=B_{0}-\frac{B_{0} t}{N_{0}}$. Because $p^{*}$ and $\tilde{p}$ are intersections of increasing function $F^{-1}(p)$ with $\Pi_{0}(p)$ and $\Pi_{1}(p)$ respectively in their decreasing parts, $p^{*}<\tilde{p}$. Similarly, since $p^{t}$ and $\tilde{p}^{t}$ are intersections of $F^{-1}(p)$ with $\Pi_{0}(p)$ and $\Pi_{1}(p)$ respectively in their increasing parts, $p^{t}>\tilde{p}^{t}$. Thus, equilibrium participation is decreasing and participation threshold is increasing in population size.

3. Suppose coordination equilibrium exists for some values $N, B$ and cost distribution $F$ : equilibrium participation level is $p^{*}$ and participation threshold is $p^{t}$. Then, according to Proposition 1 coordination equilibrium exists for the same $N, B$ and any cost distribution $G$ which is first-order stochastically dominated by $F$. Denote participation level under this equilibrium as $\tilde{p}$ and participation threshold as $\tilde{p}^{t}$. Let us show that $p^{*}<\tilde{p}$ and $p^{t}>\tilde{p}^{t}$. 
Assume by contrast that $p^{*}>\tilde{p}$, and recall that, to be an equilibrium, both $p^{*}$ and $\tilde{p}$ must be greater than or equal to $\frac{N / 2}{B-1}$. Then $F^{-1}\left(p^{*}\right)>G^{-1}(\tilde{p})$. Because $p^{*}$ satisfies $\Pi\left(p^{*}\right)=F^{-1}\left(p^{*}\right)$ and $\tilde{p}$ satisfies $\Pi(\tilde{p})=G^{-1}(\tilde{p})$ it must be that $\Pi\left(p^{*}\right)>\Pi(\tilde{p})$. But $\Pi$ is a decreasing function for any $p \geq \frac{N / 2}{B-1}$, implying that $p^{*}<\tilde{p}$, which contradicts the initial assumption. Thus, $p^{*}<\tilde{p}$.

Since $p^{t}$ and $\tilde{p}^{t}$ are intersections of the increasing part of $\Pi(p)$ with $F^{-1}(p)$ and $G^{-1}(p)$ respectively, and $F^{-1}(p) \geq G^{-1}(p)$ for all $p$, it immediately follows that $p^{t}>\tilde{p}^{t}$.

Proof of Lemma 1. Denote $F(\tilde{c})=p$ for shorter notation. Then

$$
\begin{gathered}
w_{B}=\sum_{i=N / 2+1}^{B}\left(\begin{array}{c}
B \\
i
\end{array}\right) p^{i}(1-p)^{B-i}, \\
v_{B}=\sum_{i=N / 2+1}^{B-1}\left(\begin{array}{c}
B-1 \\
i
\end{array}\right) p^{i}(1-p)^{B-i-1} .
\end{gathered}
$$

Consider the first element of $w_{B}$ and, since $\left(\begin{array}{c}B \\ j\end{array}\right)=\left(\begin{array}{c}B-1 \\ j-1\end{array}\right)+\left(\begin{array}{c}B-1 \\ j\end{array}\right)$ for all $j<B$, rewrite it as:

$$
\begin{aligned}
w_{B}^{1}=\left(\begin{array}{c}
B \\
N / 2+1
\end{array}\right) p^{N / 2+1}(1-p)^{B-N / 2-1} & =\left(\begin{array}{c}
B-1 \\
N / 2
\end{array}\right) p^{N / 2+1}(1-p)^{B-N / 2-1}+\left(\begin{array}{c}
B-1 \\
N / 2+1
\end{array}\right) p^{N / 2+1}(1-p)^{B-N / 2-1} . \\
w_{B}^{1} & =p \Pi(p)+(1-p) v_{B}^{1} .
\end{aligned}
$$

The second element of $w_{B}$ can be expressed as

$$
\begin{gathered}
w_{B}^{2}=\left(\begin{array}{c}
B \\
N / 2+2
\end{array}\right) p^{N / 2+2}(1-p)^{B-N / 2-2}=\left(\begin{array}{c}
B-1 \\
N / 2+1
\end{array}\right) p^{N / 2+2}(1-p)^{B-N / 2-2}+ \\
+\left(\begin{array}{c}
B-1 \\
N / 2+2
\end{array}\right) p^{N / 2+2}(1-p)^{B-N / 2-2} .
\end{gathered}
$$

Which is equivalent to

$$
w_{B}^{2}=p v_{B}^{1}+(1-p) v_{B}^{2}
$$

Similarly, any $j^{t h}$ element of $w_{B}$ except the first and the last ones $(2 \leq j \leq B-N / 2-1)$ can be expressed as:

$$
w_{B}^{j}=p v_{B}^{j-1}+(1-p) v_{B}^{j} .
$$


The last element of $w_{B}$ equals

$$
w_{B}^{B-N / 2}=p^{B}=p p^{B-1}=p v_{B}^{B-N / 2-1},
$$

where $v_{B}^{B-N / 2-1}$ is the last element of $v_{B}$. Summing all the elements of $w_{B}$ :

$$
w_{B}=\sum_{j=1}^{B-N / 2} w_{B}^{j}=\sum_{k=1}^{B-N / 2-1} v_{B}^{k}+p \Pi(p)=v_{B}+p \Pi(p)
$$

Proof of Lemma 2. Recall the following identity ${ }^{9}$ :

$$
1-I_{x}(a, b)=(1-x)^{a+b-1} \sum_{i=0}^{a-1}\left(\begin{array}{c}
a+b-1 \\
i
\end{array}\right)\left(\frac{x}{1-x}\right)^{i}
$$

where $I_{x}(a, b)$ is regularized incomplete beta-function. Denote $F(\tilde{c})=p$ for shorter notation. Then

$$
w_{B}=\sum_{i=N / 2+1}^{B}\left(\begin{array}{c}
B \\
i
\end{array}\right) p^{i}(1-p)^{B-i}
$$

Consider the following regularized incomplete beta-function: $I_{p}(N / 2+1, B-N / 2)$. Using the identity above:

$$
1-I_{p}(N / 2+1, B-N / 2)=(1-p)^{B} \sum_{i=0}^{N / 2}\left(\begin{array}{c}
B \\
i
\end{array}\right)\left(\frac{p}{1-p}\right)^{i}=\sum_{i=0}^{N / 2}\left(\begin{array}{c}
B \\
i
\end{array}\right) p^{i}(1-p)^{B-i}=1-w_{B}
$$

Hence, $w_{B}=I_{p}(N / 2+1, B-N / 2)$.

Also recall Chebyshev's integral:

$$
\int x^{a}(1-x)^{b} \mathrm{~d} x=B_{x}(a+1, b+1)
$$

where $B_{x}(a+1, b+1)$ is incomplete beta-function.

Thus, $\int \Pi(p) \mathrm{d} p$ can be expressed as $\left(\begin{array}{c}B-1 \\ N / 2\end{array}\right) B_{p}(N / 2+1, B-N / 2)$. By definition of regularized incomplete beta-function:

$$
I_{p}(N / 2+1, B-N / 2)=\frac{B_{p}(N / 2+1, B-N / 2)}{\mathrm{B}(N / 2+1, B-N / 2)},
$$

\footnotetext{
${ }^{9}$ See, for example, Pearson, K., 1968. Tables of Incomplete Beta-Function, Second Edition, Cambridge University Press, page 28.
} 
where $\mathrm{B}(N / 2+1, B-N / 2)$ is beta-function.

Since $\mathrm{B}(N / 2+1, B-N / 2)=\frac{(N / 2) !(B-N / 2-1) !}{B !}$ :

$$
\begin{gathered}
B \int \Pi(p) \mathrm{d} p=B\left(\begin{array}{c}
B-1 \\
N / 2
\end{array}\right) B_{p}(N / 2+1, B-N / 2)=\frac{B !}{(N / 2) !(B-N / 2-1) !} B_{p}(N / 2+1, B-N / 2)= \\
=\frac{B_{p}(N / 2+1, B-N / 2)}{\mathrm{B}(N / 2+1, B-N / 2)}=I_{p}(N / 2+1, B-N / 2)=w_{B}
\end{gathered}
$$

Hence, $B \int \Pi(p) \mathrm{d} p=w_{B}$. To complete the proof it is sufficient to differentiate both parts of the last identity with respect to $p$.

Proof of Proposition 3. Welfare as a function of some strategy $\tilde{c}$ is expressed as

$$
W=(N-B)\left(1-w_{B}\right)+B v_{B}+B \int_{0}^{\tilde{c}}(\Pi(F(\tilde{c}))-c) \mathrm{d} F(c) .
$$

In full abstention equilibrium, where $\tilde{c}=0$ and both $w_{B}=0$ and $v_{B}=0$, social welfare is then simply $N-B$. Consider the difference between welfare in coordination equilibrium and welfare in full abstention equilibrium:

$$
\Delta W=B v_{B}-(N-B) w_{B}+B \int_{0}^{c^{*}}\left(\Pi\left(F\left(c^{*}\right)\right)-c\right) \mathrm{d} F(c) .
$$

According to Lemma $1 w_{B}=v_{B}+\Pi(F(\tilde{c})) F(\tilde{c})$. Then $\Delta W$ is simply

$$
\Delta W=(2 B-N) w_{B}-B \int_{0}^{c^{*}} c \mathrm{~d} F(c) .
$$

Since $\int_{0}^{c^{*}} c \mathrm{~d} F(c)<\Pi\left(F\left(c^{*}\right)\right)$ and $F\left(c^{*}\right) \geq \frac{N / 2}{B-1}$, one might obtain a lower bound for $\Delta W$ :

$$
\begin{gathered}
(2 B-N) w_{B} \geq(2 B-N) \sum_{i=N / 2+1}^{B}\left(\begin{array}{c}
B \\
i
\end{array}\right)\left(\frac{N / 2}{B-1}\right)^{i}\left(\frac{B-N / 2-1}{B-1}\right)^{B-i}, \\
B \int_{0}^{c^{*}} c \mathrm{~d} F(c)<B \Pi\left(F\left(c^{*}\right)\right) \leq B\left(\begin{array}{c}
B-1 \\
N / 2
\end{array}\right)\left(\frac{N / 2}{B-1}\right)^{N / 2}\left(\frac{B-N / 2-1}{B-1}\right)^{B-N / 2-1}, \\
\Delta W>(2 B-N) \sum_{i=N / 2+1}^{B}\left(\begin{array}{c}
B \\
i
\end{array}\right)\left(\frac{N / 2}{B-1}\right)^{i}\left(\frac{B-N / 2-1}{B-1}\right)^{B-i}-
\end{gathered}
$$




$$
-B\left(\begin{array}{c}
B-1 \\
N / 2
\end{array}\right)\left(\frac{N / 2}{B-1}\right)^{N / 2}\left(\frac{B-N / 2-1}{B-1}\right)^{B-N / 2-1} .
$$

Note that the lower bound for $\Delta W$ is a function of two integers $B$ and $N$ such that $N / 2+1 \leq B \leq N$. It can be shown that the lower bound is increasing in $B$ for a fixed value of $N$. To verify this it is sufficient to go over all possible values of $N$, and check monotonicity for each value of it and for all $N / 2+1 \leq B \leq N$. For this paper monotonicity is checked for all even integers $N \in[2,1000000]$. Further, the lower bound for $\Delta W$ is positive for $B=N$. To see that, it is sufficient to take the first two elements from the sum in the expression for the lower bound evaluated at $B=N$, and observe that for any $N \geq 2$ :

$$
\begin{aligned}
& \frac{N}{(N-1)^{N}}\left(\left(\begin{array}{c}
N \\
N / 2+1
\end{array}\right)(N / 2)^{N / 2+1}(N / 2-1)^{N / 2-1}+\left(\begin{array}{c}
N \\
N / 2+2
\end{array}\right)(N / 2)^{N / 2+2}(N / 2-1)^{N / 2-2}\right)- \\
& -\frac{N}{(N-1)^{N-1}}\left(\begin{array}{c}
N-1 \\
N / 2
\end{array}\right)(N / 2)^{N / 2}(N / 2-1)^{N / 2-1}= \\
& \frac{N}{(N-1)^{N}}\left(\begin{array}{c}
N-1 \\
N / 2
\end{array}\right)(N / 2)^{N / 2}(N / 2-1)^{N / 2-1} \\
& \cdot\left(\frac{N}{N / 2+1}(N / 2)+\frac{N}{(N / 2+1)(N / 2+2)}(N / 2)^{2}-(N-1)\right)= \\
& \frac{N^{2}}{(N-1)^{N}}\left(\begin{array}{c}
N-1 \\
N / 2
\end{array}\right)(N / 2)^{N / 2}(N / 2-1)^{N / 2-1} \\
& \left.\cdot\left(\frac{N / 2}{N / 2+1}+\frac{(N / 2)^{2}}{(N / 2+1)(N / 2+2)}-1+1 / N\right)\right)= \\
& \left.\frac{N^{2}}{(N-1)^{N}}\left(\begin{array}{c}
N-1 \\
N / 2
\end{array}\right)(N / 2)^{N / 2}(N / 2-1)^{N / 2-1}\left(\frac{N}{N / 2+2}-1+1 / N\right)\right)>0 .
\end{aligned}
$$

Since the lower bound for $\Delta W$ is increasing in $B$ and positive for $B=N$, for any $N$ there exists $B_{0}>N / 2$ such that for any $B_{0} \leq B \leq N \Delta W>0$.

Proof of Proposition 4. If all the voters abstain, an A-type voter is never pivotal, while a B-type voter is pivotal if and only if none of the non-participants' votes is stolen. Thus, the expected benefit function of a B-type voter at point $\left(c_{\min }, c_{\min }\right)$, which corresponds to full abstention, is $\Pi_{B}\left(c_{\min }, c_{\min }\right)=(1-\alpha)^{N-1}$, which is strictly decreasing in $\alpha$. Since at $\alpha=0$ pivotal function $\Pi_{B}\left(c_{\text {min }}, c_{\text {min }}\right)=1>c_{\text {min }}$, and at $\alpha=1 \Pi_{B}\left(c_{\text {min }}, c_{\text {min }}\right)=0<c_{\text {min }}$, there exists 
a unique value of $\alpha=\alpha_{0}$ such that $\Pi_{B}\left(c_{\text {min }}, c_{\text {min }}\right)=c_{\text {min }}$. For any $\alpha \geq \alpha_{0} \Pi_{B}\left(c_{\text {min }}, c_{\text {min }}\right)<c_{\text {min }}$, implying that deviation from abstention is never profitable for a B-type voter, and for any $\alpha<\alpha_{0}$ $\Pi_{B}\left(c_{\text {min }}, c_{\text {min }}\right)>c_{\text {min }}$, implying that deviation is profitable, and thus, full abstention is not an equilibrium. 


\section{Appendix B}

Proof of Lemma 3. Consider two functions:

$$
\begin{aligned}
& \Pi_{0}(p)=\left(\begin{array}{c}
B_{0}-1 \\
N_{0} / 2
\end{array}\right) p^{N_{0} / 2}(1-p)^{B_{0}-N_{0} / 2-1}, \\
& \Pi_{1}(p)=\left(\begin{array}{c}
B_{1}-1 \\
N_{1} / 2
\end{array}\right) p^{N_{1} / 2}(1-p)^{B_{1}-N_{1} / 2-1},
\end{aligned}
$$

where $N_{1}=N_{0}-t, t \geq 2$, and $t / 2$ as well as $\frac{B_{0} t}{N_{0}}$ are integers.

Rewriting $\Pi_{0}(p)$ in terms of $\Pi_{1}(p)$ and denoting $N_{1} / 2=x, t / 2=m, B_{1}=B$ for shorter notation:

$$
\begin{gathered}
\Pi_{0}(p)=\left(\begin{array}{c}
B+\frac{B m}{x}-1 \\
x+m
\end{array}\right) p^{x+m}(1-p)^{B+\frac{B m}{x}-x-m-1}, \\
\Pi_{1}(p)=\left(\begin{array}{c}
B-1 \\
x
\end{array}\right) p^{x}(1-p)^{B-x-1},
\end{gathered}
$$

To show that $\Pi_{0}(p) \leq \Pi_{1}(p)$ it is sufficient to show that

$$
\left(\begin{array}{c}
B+\frac{B m}{x}-1 \\
x+m
\end{array}\right) p^{x+m}(1-p)^{B+\frac{B m}{x}-x-m-1}-\left(\begin{array}{c}
B-1 \\
x
\end{array}\right) p^{x}(1-p)^{B-x-1} \leq 0
$$

or, equivalently, that

$$
\frac{\left(\begin{array}{c}
B+\frac{B m}{x}-1 \\
x+m
\end{array}\right)}{\left(\begin{array}{c}
B-1 \\
x
\end{array}\right)} p^{m}(1-p)^{\frac{B m}{x}-m} \leq 1
$$

Note that function $g(p)=p^{m}(1-p)^{\frac{B m}{x}-m}$ achieves its maximum at $p=x / B$, and thus to complete the proof it is sufficient to show that

$$
\frac{\left(\begin{array}{c}
B+\frac{B m}{x}-1 \\
x+m
\end{array}\right)}{\left(\begin{array}{c}
B-1 \\
x
\end{array}\right)} \frac{x^{m}(B-x)^{\frac{B m}{x}}}{B^{\frac{B m}{x}}} \leq 1
$$

The last expression can be rewritten as

$$
\begin{gathered}
\frac{B(B+1) \ldots\left(B+\frac{B m}{x}-1\right)}{(x+1) \ldots(x+m)(B-x)(B-x+1) \ldots\left(B-x+\frac{B m}{x}-m-1\right)} \frac{x^{m}(B-x)^{\frac{B m}{x}}}{B^{\frac{B m}{x}}}= \\
=\frac{1\left(1+\frac{1}{B}\right) \ldots\left(1+\frac{m}{x}-\frac{1}{B}\right)}{\left(1+\frac{1}{x}\right) \ldots\left(1+\frac{m}{x}\right) 1\left(1+\frac{1}{B-x}\right) \ldots\left(1+\frac{\frac{B m}{x}-m-1}{B-x}\right)} .
\end{gathered}
$$

Drop 1 from the nominator and denominator of the last expression and note that the nominator consists of $\frac{B m}{x}-1$ elements which are ordered from the smallest to the largest since 
$B>x$ and $m \geq 1$. The denominator consists of two groups of elements. The first group consists of $m$ elements of the form $\left(1+\frac{i}{x}\right), i=1 \ldots m$. The second group consists of $\frac{B m}{x}-m-1$ elements of the form $\left(1+\frac{i}{B-x}\right), i=1 \ldots \frac{B m}{x}-m-1$. Within each group the elements are ordered from the smallest to the largest, but the entire denominator is not ordered since $1+\frac{m}{x}>1+\frac{m}{x}-\frac{1}{B-x}=$ $1+\frac{\frac{B m}{x}-m-1}{B-x}$.

First, inverse the orders of the elements in the nominator and in each group in the denominator:

$$
\frac{\left(1+\frac{m}{x}-\frac{1}{B}\right)\left(1+\frac{m}{x}-\frac{2}{B}\right) \ldots\left(1+\frac{1}{B}\right)}{\left(1+\frac{m}{x}\right)\left(1+\frac{m-1}{x}\right) \ldots\left(1+\frac{1}{x}\right)\left(1+\frac{m}{x}-\frac{1}{B-x}\right)\left(1+\frac{m}{x}-\frac{2}{B-x}\right) \ldots\left(1+\frac{1}{B-x}\right)} .
$$

Then, let us sort all the elements in the denominator from the largest to the smallest. The largest element among all the elements of the denominator is $1+\frac{m}{x}$, and the second largest is $1+\frac{m-1}{x}$ since $1+\frac{m-1}{x}>1+\frac{m}{x}-\frac{1}{B-x}$. Further ordering depends on the value of $\frac{B}{x}$ ratio: if $B \leq \frac{3}{2} x$ the third largest element is $\left(1+\frac{m-2}{x}\right)$, otherwise it is $\left(1+\frac{m}{x}-\frac{1}{B-x}\right)$, the largest element of the second group.

Clearly, for any value of $\frac{B}{x}$ there is a unique ordering of the denominator. In this ordering, the k-th element of the second group $\left(1+\frac{m}{x}-\frac{k}{B-x}\right)$ will be placed exactly between 1 -th $\left(1+\frac{m}{x}-\frac{l-1}{x}\right)$ and $(1+1)$-th $\left(1+\frac{m}{x}-\frac{l}{x}\right)$ elements of the first group, where $l$ is such that $\frac{k+l}{l} \leq \frac{B}{x} \leq \frac{k+l-1}{l-1}$, and its position in the entire sequence of the elements in the denominator will be $(l+1+k-1)$. Note, that if $\frac{B}{x} \leq \frac{m}{m-1}$ all the elements of the second group are smaller than the smallest element of the first group $\left(1+\frac{1}{x}\right)$.

Now compare this $(1+\mathrm{k})$-th element of the ordered denominator with the element of the nominator in the same position: $1+\frac{m}{x}-\frac{l+k}{B} \leq 1+\frac{m}{x}-\frac{k}{B-x}$ as long as $\frac{k+l}{l} \leq \frac{B}{x}$ which is a part of the condition for the element $\left(1+\frac{m}{x}-\frac{l+k}{B}\right)$ to be on $(1+\mathrm{k})$-th place.

Similarly, the 1 -th element $(l \geq 3)$ of the first group $\left(1+\frac{m}{x}-\frac{l-1}{x}\right)$ will appear after the $\mathrm{k}$-th element and before the $(\mathrm{k}+1)$-the element of the second group whenever $\frac{k+l-1}{l-1} \leq \frac{B}{x}<\frac{k+l}{l-1}$, and its position in ordered sequence will be $(l+k)$. The element in the corresponding position in the nominator is $1+\frac{m}{x}-\frac{l+k}{B}<1+\frac{m}{x}-\frac{l-1}{x}$ whenever $\frac{B}{x} \leq \frac{k+l}{l-1}$. The first two elements of the first group are always the largest in the entire sequence, and $1+\frac{m}{x}>1+\frac{m}{x}-\frac{1}{B}, 1+\frac{m-1}{x} \geq 1+\frac{m}{x}-\frac{2}{B}$. Thus, for all $n=1 \ldots \frac{B m}{x}-1$ the $\mathrm{n}$-th element of the ordered denominator is greater than or equal to the n-th element of the nominator, and thus the entire expression does not exceed 1. 


\section{References}

Beck, T., Clarke, G., Groff, A., Keefer P., Walsh, P., 2001. New Tools and New Tests in Comparative Political Economy: the Database of Political Institutions. World Bank Economic Review, $15,165-176$.

Borgers, T., 2004. Costly Voting. American Economic Review, 94 (1), 57-66.

Birch, S., 2010. Perceptions of Electoral Fairness and Voter Turnout. Comparative Political Studies, 43(12), 1601-1622.

Chaturvedi, A., 2005. Rigging Elections with Violence. Public Choice, 125, 189-202.

Chakravarty, S., Kaplan, T., Myles, G., 2010. The Benefits of Costly Voting. Working Paper. University of Exeter Business School.

Collier, P., Vicente, P., 2012. Violence, Bribery, and Fraud: The Political Economy of Elections in Sub-Saharan Africa, Public Choice, 153 (1-2), 117-147.

Ghosal, S., Lockwood, B., 2009. Costly Voting when Both Information and Preferences Differ: Is Turnout Too High or Too Low? Social Choice and Welfare, 33 (1), 25-50.

Hiskey, J., Bowler, S., 2005. Local Context and Democratization in Mexico. American Journal of Political Science, 49 (1), 57-71.

Krasa, S., Polborn, M., 2009. Is Mandatory Voting Better than Voluntary Voting? Games and Economic Behavior, 66, 275-291.

Krishna, V., Morgan, J., 2012. Voluntary Voting: Costs and Benefits. Journal of Economic Theory, forthcoming.

Landry, P., Davis, D., Wang, S., 2010. Elections in Rural China: Competition without Parties. Comparative Political Studies, 15, 763-790.

Lehoucq, F., 2003. Electoral Fraud: Causes, Types and Consequences. Annual Review of Political Science, 6, 233-256.

Ledyard, J., 1984. The Pure Theory of Large Two-Candidate Elections. Public Choice, 44, 7-41.

Magaloni, B., 2010. The Game of Electoral Fraud and the Ousting of Authoritarian Rule. American Journal of Political Science, 54 (3), 751-765. 
McCann, J., Dominguez, J.,1998. Mexicans React to Political Fraud and Corruption: An Assessment of Public Opinion and Voting Behavior. Electoral Studies, 17, 483-503.

Palfrey, T., Rosenthal, H., 1983. A Strategic Calculus of Voting. Public Choice, 41(1), 7-53.

Palfrey, T., Rosenthal, H., 1985. Voter Participation and Strategic Uncertainty. American Political Science Review, 79 (1), 62-78.

Pastor, R., 1999. The Role of Electoral Administration in Democratic Transitions. Democratization, 6, 1-27.

Riker, W., Ordeshook, P., 1968. A Theory of the Calculus of Voting. American Political Science Review, 62, 28-42.

Simpser, A., 2008. Cheating Big: On the Logic of Electoral Corruption in Developing Countries. Working Paper, University of Chicago.

Simpser, A., 2008. The Measurement of Electoral Corruption: Some Issues and a Cross-National Dataset. Working Paper, University of Chicago.

Simpser, A., 2012. Does Electoral Manipulation Discourage Voter Turnout? Evidence from Mexico. Journal of Politics, 74 (3), 782-795.

Taylor, C., Yildirim, H., 2010. A Unified Analysis of Rational Voting with Private Values and Group-Specific Costs. Games and Economic Behavior, 70 (2), 457-471. 


\section{Working Paper Series}

ISSN 1211-3298

Registration No. (Ministry of Culture): E 19443

Individual researchers, as well as the on-line and printed versions of the CERGE-EI Working Papers (including their dissemination) were supported from institutional support RVO 67985998 from Economics Institute of the ASCR, v. v. i.

Specific research support and/or other grants the researchers/publications benefited from are acknowledged at the beginning of the Paper.

(c) Dmitriy Vorobyev, 2014

All rights reserved. No part of this publication may be reproduced, stored in a retrieval system or transmitted in any form or by any means, electronic, mechanical or photocopying, recording, or otherwise without the prior permission of the publisher.

Published by

Charles University in Prague, Center for Economic Research and Graduate Education (CERGE) and

Economics Institute of the ASCR, v. v. i. (EI)

CERGE-El, Politických vězňů 7, 11121 Prague 1, tel.: +420 224005 153, Czech Republic.

Printed by CERGE-EI, Prague

Subscription: CERGE-EI homepage: http://www.cerge-ei.cz

Phone: + 420224005153

Email: office@cerge-ei.cz

Web: http://www.cerge-ei.cz

Editor: Marek Kapička

The paper is available online at http://www.cerge-ei.cz/publications/working_papers/.

ISBN 978-80-7343-314-7 (Univerzita Karlova. Centrum pro ekonomický výzkum a doktorské studium)

ISBN 978-80-7344-307-8 (Akademie věd České republiky. Národohospodářský ústav) 
CERGE-EI

P.O.BOX 882

Politických vězňů 7

11121 Praha 1

Czech Republic http://www.cerge-ei.cz 